\title{
EL ROL DEL ESPACIO PÚBLICO EN LOS GRANDES PROYECTOS URBANOS ESTATALES \\ Comparativa de casos en Ecuador, Colombia y Argentina
}

\author{
Arq. Anabella Roitman - Mgr. en Planificación Urbana y Regional \\ Colaboradores. Arq. Cecilia santiago, Andres Vecchio \\ Programa Urbanismo y Ciudad + Instituto de Espacialidad Humana + Gestión Urbana Contemporánea GUC \\ - Cátedra Szajnberg. Universidad de Buenos Aires, Facultad de Arquitectura, Diseño y Urbanismo - FADU \\ anabellaroitman@gmail.com
}

\section{RESUMEN}

Esta ponencia se propone realizar una comparativa entre casos de intervenciones estatales recientes vinculadas a la generación de Nuevo Espacio Público en las ciudades de Guayaquil, Medellín y Buenos Aires, y analizar los modelos de gestión propuestos, los actores involucrados, y los impactos generados. Las ciudades seleccionadas poseen como patrón común la existencia de grandes inequidades sociohabitacionales dentro de sus jurisdicciones, a la vez que se encuentran activas en la implementación de variados instrumentos urbanísticos, y la ejecución de intervenciones urbanas de gran escala con eje en el Espacio Público.

A partir de los casos elegidos, se apunta a analizar el carácter de cada intervención en clave socio - ambiental, tomando el Espacio Público como indicador principal del análisis, que abordará tanto el carácter asignado a su propia concepción, como su impacto en cada subsector en relación a las metas de "integración sociourbana" planteadas.

Palabras clave: Espacio Público - Urbanismo - Latinoamérica - políticas públicas

\begin{abstract}
It is proposed to make a comparison between cases of recent interventions related to the generation of New Public Space in the cities of Guayaquil, Medellín and Buenos Aires, and analyze the proposed management models, the stakeholders involved, and the urban impacts generated. The selected cities present, as their common pattern, the existence of large socio-residential inequalities within their jurisdictions, while they are active in the implementation of various instruments and large-scale urban interventions associated with the Public Space.

Based on the selected cases, the aim is to analyze the nature of each intervention in a socio-environmental key, taking the Public Space as the main indicator of the analysis, which will address both the character assigned to its own conception, and their impact in each subsector in relation to the goals of "socio-urban integration" proposed.
\end{abstract}

Key words: Public Space - Urbanism - Latin America - public policies 


\section{Del suelo público al espacio público}

El Espacio Público - EP - en las ciudades, opera generalmente como una suerte de termómetro de la gestión en materia de políticas urbano - ambientales. En su caracterización, a través de las intervenciones públicas, del accionar de los actores privados y de las iniciativas comunitarias, es posible sistematizar ciertos rasgos e indicadores que aportan indicios, tanto en los casos en los que se pretende legítimamente jerarquizar al EP, asociado a su condición de "espacio colectivo" y para el beneficio "de todos", como cuando se lo interviene a modo de "escenografía urbana", situación que luego habilita omisiones respecto de la actuación integral e integradora en un territorio.

El contexto latinoamericano a su vez otorga características especiales a la noción de EP, y es sobre esta temática que las áreas de gobierno locales suelen operar con gran énfasis, otorgando a este distintas connotaciones y roles en un marco de creciente desigualdad y marginalidad ${ }^{1}$. El EP latinoamericano podría asociarse entonces a los conceptos de inequidad, carencia, desorden, en la medida en que es en estos lugares donde pueden verse reflejadas las problemáticas generales de las ciudades; a la vez que se considera al EP de estos países como lugar de oportunidad, encuentro, diversidad, democratización, ya que paralelamente es en estos espacios en los cuales los colectivos sociales intentan alzar su voz, y en donde las gestiones de gobierno despliegan esfuerzos para reflejar inversión y ejecución de obras públicas.

El tema del EP, si bien ya se encuentra instalado dentro de la órbita de la investigación urbana desde hace varias décadas ${ }^{2}$, se mantiene vigente como área de investigación transversal a las que habitualmente son abordadas desde las políticas públicas (educación, vivienda, salud, trabajo, etc), al punto que tanto las reparticiones de la gestión estatal, como los ámbitos académicos y de enseñanza, instalaron dentro de sus estructuras oficinas dedicadas específicamente a su abordaje, ejecución, mantenimiento e investigación ${ }^{3}$. Estas áreas suelen combinar enfoques multidisciplinarios que enriquecen e la vez que complejizan las posibilidades de abordaje de este tema.

A su vez, el EP constituye el escenario y motivo de la lucha de los movimientos sociales que impulsan diversas causas para las cuales este concepto renueva periódicamente su significado, donde existe una construcción política dinámica del sentido del EP, asociable tanto a los mecanismos de control y a la violencia como a las denominadas "economías creativas", la "resiliencia urbana", las cuestiones vinculadas al género, la potencialidad de su diseño desde la lógica proyectual, los imaginarios y expectativas en torno a su generación, entre otros ejes de análisis e influencia.

Las ciudades en las cuales se desarrollan los tres casos seleccionados (Buenos Aires, Medellín, Guayaquil), son claros ejemplos de implementación de políticas públicas urbanísticas en contextos de desigualdad. En los tres casos, sus organismos gubernamentales de gestión urbana despliegan estrategias que en algunos casos intentan mitigar las carencias de los sectores más vulnerables de la población, a la vez que evidencian las propias contradicciones de estos actores urbanos respecto de las pujas de poder con los privados, las necesidades de los barrios y la complejidad del financiamiento, ejecución y posterior mantenimiento de estos espacios.

1 "Aunque la desigualdad del ingreso se ha reducido durante los últimos años, América Latina sigue siendo la región más desigual del mundo. En 2014, el 10\% más rico de la población de América Latina había amasado el $71 \%$ de la riqueza de la región. Según los cálculos de Oxfam, si esta tendencia continuara, dentro de solo seis años el 1\% más rico de la región tendría más riqueza que el 99\% restante". Extraído del sitio web de la Comisión Económica para América Latina y el Caribe - CEPAL. Disponible en: https://www.cepal.org/es/articulos/2016-america-latina-caribe-es-la-region-mas-desigual-mundo-comosolucionarlo

2 "El espacio público es un concepto que ha adquirido desde los años 80 particular importancia tanto en el ámbito académico como político, tomando una amplitud y una abstracción que no permite construir una definición en la cual se concreten realidades y propuestas que corrompen las necesidades reales de la ciudad y sus habitantes. Polisémico y abstracto este concepto tiene una ideología importante en la que aterrizan diferentes discursos sobre las bases disciplinarias que lo definen y diseñan". Extraído de la convocatoria al Primer Seminario Internacional sobre Espacio Público: "diseño violencia e ilusiones urbanas", a realizarse en México DF en febrero de 2018. Información disponible en: http://seminarioespaciopublico.com/programa-deactividades/

${ }^{3}$ Para los casos estudiados, las reparticiones de la gestión públicas poseen, en Buenos Aires, un Ministerio de Ambiente y Espacio Público - MAyEP; en Medellin, una Subsec. de Espacio Público, dentro de la órbita de la Secretaría de Seguridad y Convivencia; y en Guayaquil una Dirección de Uso del Espacio y Vía Pública. Sitios web disponibles en:

Buenos Aires: http://www.buenosaires.gob.ar/ambienteyespaciopublico

Medellin: https://www.medellin.gov.co/irj/portal/medellin?NavigationTarget=navurl://93ea1dacab70f2427429cca669c8d9fa

Guayaquil: http://www.guayaquil.gob.ec/direcci\%C3\%B3n-de-uso-del-espacio-y-via-publica 
Para esta investigación se eligieron casos de proyectos que constituyeran nuevos EP, o donde este concepto tuviese un peso considerable dentro de la operatoria. Además se consideraron casos en los cuales las parcelas involucradas fuesen del Estado, lo cual obliga a la reflexión respecto de cuáles son los nuevos usos e indicadores urbanísticos que se asignan a estas. Reflexionar acerca de en qué medida lo propuesto significará un beneficio que compense la ocupación de suelo urbano vacante, implica considerar que, debido a su propia constitución, el suelo es un recurso irremplazable que una vez caracterizado, es altamente complejo revertir o modificar las intervenciones realizadas.

La investigación en curso forma parte de los avances de la tesis doctoral de la Arq. Anabella Roitman en la cual se apunta a investigar la relación entre las políticas urbanísticas y las de EP que se despliegan desde los organismos del Estado, en contextos de desigualdad urbana. Dentro de esta investigación doctoral, se considera como hipótesis central la existencia de bajos niveles de correlación entre las políticas urbanísticas y las de EP, cuyas consecuencias se plasman en los resultados de los procesos de diseño, construcción, monitoreo y mantenimiento de los EP, y en su desarticulación respecto de los lineamientos estratégicos declamados en los planes de Ordenamiento Territorial locales. A su vez esta tesis plantea como segunda hipótesis, la existencia de una pluralidad de acepciones atribuidas al EP, que emergen desde las gestiones de gobierno y que son utilizadas como argumentos para justificar la realización de determinadas intervenciones, que generalmente poseen un alto nivel de impacto (ambiental, económico, social) respecto del uso del suelo público. Los objetivos de la tesis doctoral entonces se vinculan con el análisis de diferentes casos de proyectos urbanos donde el componente EP tenga alta incidencia, para generar una caracterización de estos que permita la puesta a prueba de las hipótesis planteadas.

\section{Tres países, tres ciudades, tres lugares}

Como introducción a los tres casos estudiados, en esta sección se presentan sintéticamente sus respectivos contextos urbanos y metropolitanos.

Ilustración 1: Esquema de localización de los casos de estudio. Guayaquil - Medellín - Buenos Aires. Fuente: Elaboración propia sobre cartografía Google.

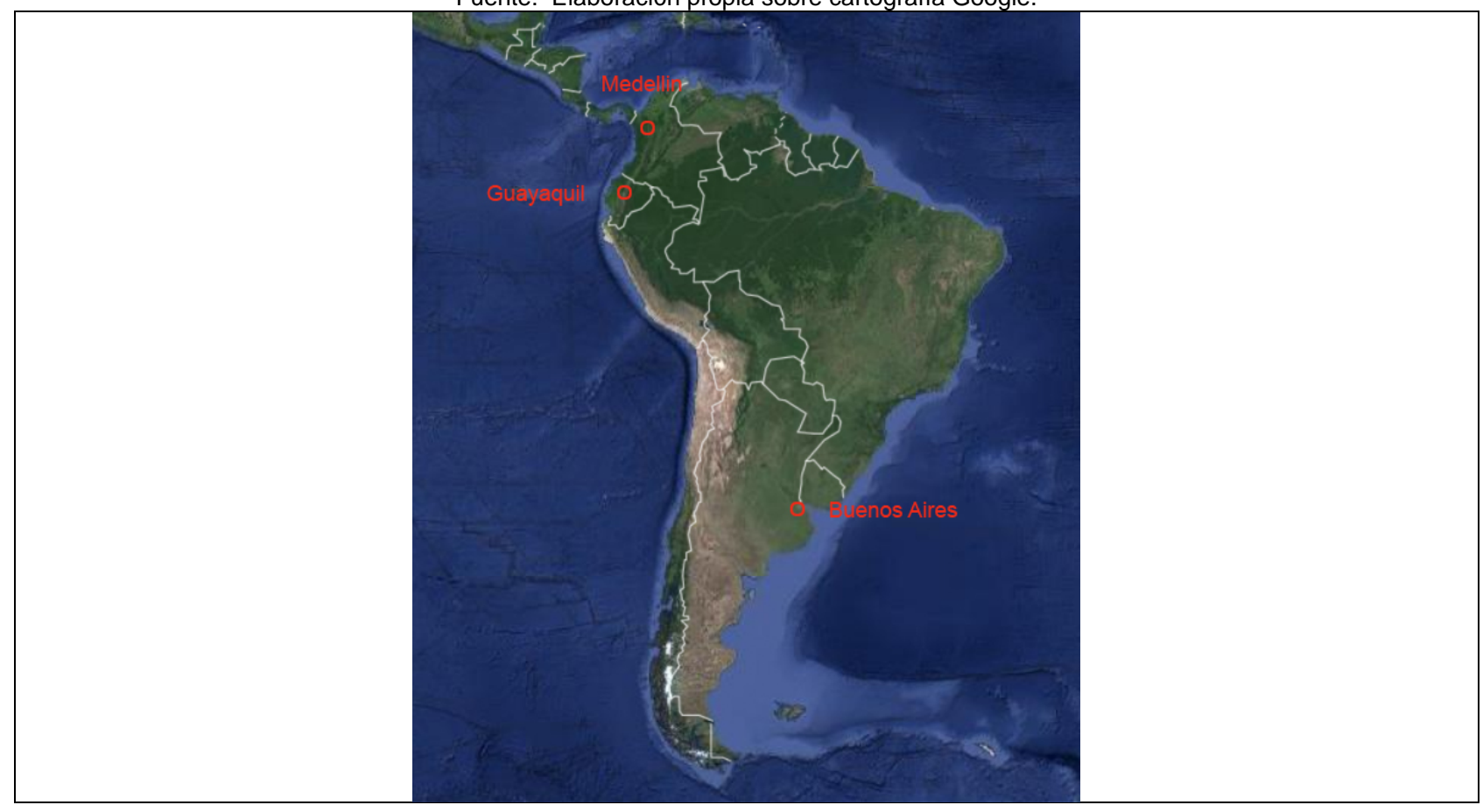

\section{Argentina}

Ilustración 2: Limite de la CABA dentro del Área metropolitana de Buenos Aires - Limites de la Comuna 8 dentro de la zona sur de la CABA - y límites de la Villa 20. Fuente: elaboración propia sobre imagen satelital Google. 


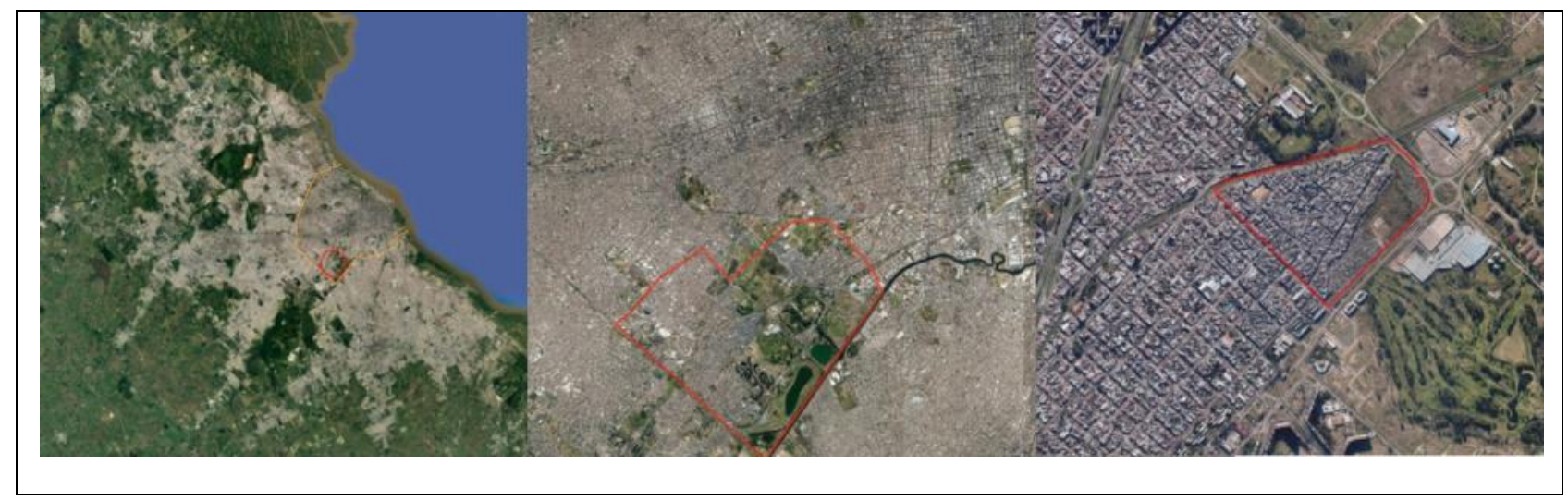

Argentina es un pais de América del Sur. Cuenta con 23 provincias más la Ciudad Autónoma de Buenos Aires, y habitan en él 40.117.096 ${ }^{4}$ millones de personas. Adopta la forma de gobierno republicana, democrática, representativa y federal.

La Ciudad Autonóma de Buenos Aires - C.A.B.A. - oficia como la capital de Argentina, y es la ciudad más poblada del país. Cuenta actualmente con 2.890 .151 habitantes $^{5}$, y esta rodeada por un area metropolitana de 14 millones de habitantes, lo que en conjunto representa el $42 \%$ de la población del país. La C.A.B.A. tiene una superficie de $203 \mathrm{~km} 2$ y una densidad de $14.994 \mathrm{hab} / \mathrm{km} 2$, y desde el año 2008 está divida administrativamente en 15 comunas con autoridades elegidas por el voto ciudadano.

La Comuna 8 - C.A.B.A está ubicada al sur de la ciudad ${ }^{6}$. Es la comuna mas extensa de la CABA, y cuenta con $187.237^{7}$ habitantes. Actualmente la Comuna 8 posee la mayor cantidad de villas de la ciudad, altas tasas de mortalidad infantil y la menor tasa de esperanza de vida de CABA. Dentro de esta Comuna se ubica la villa 20, donde habitan aprox. $28.000^{8}$ personas con carencias severas de acceso de infraestructuras básicas deequipamientos y servicios ${ }^{9}$.

\subsection{Colombia}

Ilustración 3: Límite de la Ciudad de Medellin dentro del Dto. de Antioquia- Limites de la Comuna 8 dentro de la Ciudad de Medellin - y zoom al sector del proyecto de Jardín circunvalar al oeste de la Comuna. Fuente: elaboración propia sobre imagen satelital Google

(2) Fuente: elaboración propia sobre imagen satelital Google

\footnotetext{
${ }^{4}$ Según el censo nacional de 2010. INDEC - Censo Nacional de Población, Hogares y Viviendas 2010

5 ídem cita.

${ }^{6}$ Está compuesta por 3 grandes barrios: Villa Lugano, Villa Soldati y Villa Riachuelo.

7 Ídem Cita - INDEC.

${ }^{8}$ Fuente: "Informe censo Barrio 20" - Instituto de la vivienda - IVC - Gobierno de la Ciudad de Buenos aires GCBA. disponible en http://www.buenosaires.gob.ar/sites/gcaba/files/informe_censo_barrio_20_final.pdf

${ }^{9}$ Según el citado informe del ICV, el $45 \%$ de las viviendas poseen un "estado de construcción entre regular y malo", las conexiones a la red de agua potable y eléctrica son informales, y el $91 \%$ accede al servicio de gas a través de garrafa. El 43\% de la población tiene entre 0 y 19 años, y el $57 \%$ no asiste a instituciones educativas.
} 
Colombia se ubica al noroeste de América del Sur, y se organiza en 32 departamentos ${ }^{10}$ más el Distrito Federal. Es un estado unitario, social y democrático de derecho ${ }^{11}$, y tiene una población aproximada de 48 millones de personas ${ }^{12}$.

Medellin es la capital del departamento de Antoquia, es la segunda ciudad más grande del país. Geográficamente se inserta en el Valle de Aburrá y es atravesada por el Rio Medellín. Actualmente la ciudad cuenta con 2.486 .723 habitantes ${ }^{13}$ y se extiende por $382 \mathrm{~km} 2^{15}$. A nivel administrativo, Medellín está dividida en 6 zonas y 16 comunas $^{16}$.

La Comuna 8 "Villa Hermosa" está ubicada en la zona este de la ciudad. Contiene 18 barrios. Tiene como característica la existencia de asentamientos en zonas de ladera donde se presentan zonas de riesgo ${ }^{17}$.

\subsection{Ecuador}

Ecuador se ubica al noroeste de América del Sur, y constituye una República presidencialista basada en una democracia representativa constitucional ${ }^{18}$. Dividido en 24 povincias $^{19}$ cuenta con aproximadamente 16 millones de habitantes ${ }^{20}$.

Guayaquil es la capital de la Provincia de Guayas siendo la ciudad más poblada ${ }^{21}$.del país. Situada a orillas del Rio Guayas, se extiende por $350 \mathrm{~km}^{22}$ y está organizada en 16 parroquias urbanas ${ }^{23}$ y 5 parroquias rurales. Presenta una población de 2.617.349 habitantes con una densidad 7372 hab/km2.

Ilustración 4: Límite de la Ciudad de Guayaquil dentro del Dto. de XXXX- Limites del barrio "El suburbio" dentro de la Ciudad de Guayaquil - y zoom al sector del proyecto de Parque Lineal.

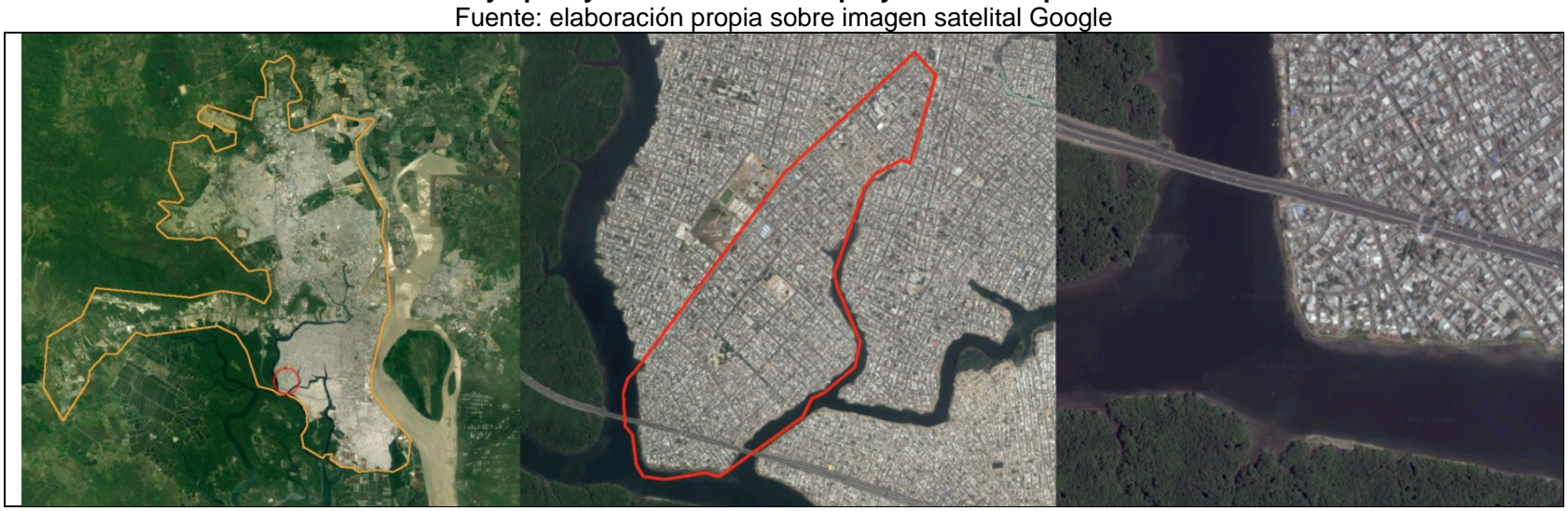

${ }^{10}$ Según Web oficial de Colombia: https://www.colombia.com/colombia-info/departamentos/

${ }^{11}$ Según la Constitución política de Colombia 1991. Disponible en: https://www.registraduria.gov.co/lMG/pdf/constituciopolitica-colombia-1991.pdf

12 Según Departamento Administrativo Nacional de Estadística 2016 -DANE.

13 Ídem Cita

15 Según documento técnico de soporte POT [acuerdo 46/2006] Municipio de Medellín. Disponible en http://sisbib.unmsm.edu.pe/BibVirtualData/publicaciones/geologia/Vol7_N13/Pdf/a05.pdf

${ }_{27}$ Según Web oficial de Colombia - División - Disponible en: http://www.guayaquil.gob.ec/divisi\%C3\%B3n.

${ }^{28}$ Según comparación de datos de Censo 2010. Situación y caracterización de los asentamientos precarios en la Ciudad de Buenos Aires y Anuario estadístico de la Ciudad de Buenos Aires. 
Como es posible visualizar en la siguiente tabla, si bien existen diferencias en relación a las formas de gobierno y a los roles de cada ciudad dentro del pais, y de cada comuna o barrio dentro de cada ciudad, es posible establecer puntos de coincidencia respecto de los 3 casos seleccionados, en relacion a su localización periférica en contextos de desigualdad urbana severa respecto de los indicadores sociohabitacionales de las areas servidas de las mismas ciudades, que a su vez poseen extensas areas metropolitanas.

\begin{tabular}{|c|c|c|c|}
\hline PAÍS & ARGENTINA & COLOMBIA & ECUADOR \\
\hline $\begin{array}{l}\text { Forma de } \\
\text { gobierno }\end{array}$ & $\begin{array}{l}\text { republicana, democrática, } \\
\text { representativa y federal. }\end{array}$ & $\begin{array}{l}\text { estado unitario, social y democrático } \\
\text { de derecho }\end{array}$ & $\begin{array}{l}\text { República presidencialista basada en } \\
\text { una democracia representativa } \\
\text { constitucionalmente establecida. }\end{array}$ \\
\hline Org. territorial & 23 provincias + Ciudad Autonoma & 32 departamentos + Distrito Capital & 24 provincias \\
\hline CIUDAD & BUENOS AIRES & MEDELLIN & GUAYAQUIL \\
\hline Cant.hab. & $2.890 .151 \mathrm{hab}$ & 2.486.723 hab & 2.617.349 hab \\
\hline Superficie & 203 km2 & $382 \mathrm{~km} 2$ & $350 \mathrm{~km} 2$ \\
\hline Densidad & $14.994 \mathrm{hab} / \mathrm{km} 2$ & $6509 \mathrm{hab} / \mathrm{km} 2$ & $7372 \mathrm{hab} / \mathrm{km} 2$ \\
\hline $\begin{array}{c}\text { Rol de la } \\
\text { Ciudad dentro } \\
\text { del país }\end{array}$ & $\begin{array}{c}\text { Capital del pais. Ciudad mas grande } \\
\text { y poblada del pais. }\end{array}$ & $\begin{array}{c}\text { Capital del departamento de } \\
\text { Antioquia. La segunda ciudad más } \\
\text { poblada del país. }\end{array}$ & $\begin{array}{l}\text { Capital de la Provincia de Guayas. } \\
\text { Ciudad más poblada del pais }\end{array}$ \\
\hline $\begin{array}{c}\text { Nivel de } \\
\text { marginalidad }\end{array}$ & $\begin{array}{c}\text { El 6\% de la población de Buenos } \\
\text { Aires vive en Villas, Asentamientos } \\
\text { o } \mathrm{NHT}^{30}\end{array}$ & $\begin{array}{c}\text { El } 47.37 \% \text { de la población vive en } \\
\text { condiciones de vivienda bajo o bajo } \\
\text { bajo. } 31\end{array}$ & $\begin{array}{c}\text { El } 15 \% \text { de la población de } \\
\text { Guayaquil es considerada pobre } \\
\text { el } 6 \% \text { de las viviendas son ranchos } \\
\text { covachas o chozas }^{33} \text {. }\end{array}$ \\
\hline BARRIO & VILLA LUGANO - Comuna 8 & VILLA HERMOSA - Comuna 8 & BATALLON DEL SUBURBIO \\
\hline Caracter. & $\begin{array}{c}\text { Comuna con mayor cantidad de } \\
\text { villas y asentamientos en la ciudad } \\
34 .\end{array}$ & $\begin{array}{l}\text { Asentamientos espontaneos o } \\
\text { clandestinos. El } 73 \% \text { de las viviendas } \\
\text { están dentro de los estratos de } \\
\text { vivienda "bajo" y "bajo bajo" } 35\end{array}$ & $\begin{array}{l}\text { En las orillas del rio presentaba } \\
\text { asentamientos en zonas de riesgo } \\
\text { de contaminación. }{ }^{36}\end{array}$ \\
\hline
\end{tabular}

\section{3 . Metodología utilizada}

Esta ponencia es producto de las actividades de transferencia e investigación realizadas desde el Proyecto UBACyT 20020160100057BA01 - "Gestión Urbana Contemporánea y Justicia Socio-Espacial" - (Directora D. Szajnberg); la investigación en el marco del Doctorado FADU - UBA y dentro del Programa de Jóvenes Docentes Investigadores (Sec. de Investigaciones - FADU - UBA - Unidad de Investigación: Planificación Urbana y Regional) de la Arq. Anabella Roitman; y como transferencia de la materia Gestión Urbana Contemporánea cátedra Szajnberg 2017 - Universidad de Buenos Aires, Facultad de Arquitectura, Diseño y Urbanismo. En el proceso de investigación participaron una investigadora formada ${ }^{37}$, acompañada de una arquitecta investigadora que inicia sus actividades ${ }^{38}$, y un pasante estudiante avanzado de la carrera de arquitectura $^{39}$, en el marco del citado equipo UBACyT.

Para el análisis de los casos seleccionados de procedió a realizar una matriz - cuadro de doble entrada, en el cual se fue recopilando la información respecto de estos proyectos, agrupada en los siguientes ejes:

${ }^{29}$ Según Instituto Nacional de Estadísticas y Censos (INEC) datos de Censo 2010.

30 Según Censo 2010. Situación y caracterización de los asentamientos precarios en la Ciudad de Buenos Aires. 170.054 personas viven en Villas, Asentamientos o NHT.

${ }^{31}$ Según la publicacion: "Perfil socioeconómico de Medellín. Encuesta calidad de vida 2013". Disponible en: http://www.metropol.gov.co/observatorio/Publicaciones/Perfil/Perfil\%20Municipal_Medellin.pdf

32 Según Estratificación social de viviendas. Disponible en: https://www.medellin.gov.co/irj/go//km/docs/wpccontent/Sites/Subportal\%20del\%20Ciudadano/Planeaci\%C3\%B3n\%20Municipal/Seccio nes/Indicadores\%20y\%20Estad\%C3\%ADsticas/Documentos/Estratificaci\%C3\%B3n/EstimadoViviendasDiciembre30_2011.pdf

${ }^{33}$ Según Instituto Nacional de Estadísticas y Censos - INEC. Censo de Población 2010. Sus ingresos no superan $\$ 80$ al mes.

34 Según Censo 2010. Situación y caracterización de los asentamientos precarios en la Ciudad de Buenos Aires. De las 42 Villas, Asentamientos o NHT revelado, 17 se encuentran en esta Comuna donde el $28 \%$ de población vive en Villas, Asentamientos o NHT.

${ }_{35}$ Según Estratificación social de viviendas. Disponible en: https://www.medellin.gov.co/irj/go/km/docs/wpccontent/Sites/Subportal\%20del\%20Ciudadano/Planeaci\%C3\%B3n\%20Municipal/Seccio nes/Indicadores\%20y\%20Estad\%C3\%ADsticas/Documentos/Estratificaci\%C3\%B3n/EstimadoViviendasDiciembre30 2011.pdf

${ }^{36}$ Según Diario Expreso "La reubicación de familias junto al estero no avanza y estas siguen descargando" publicado el 11 de marzo del 2016. Disponible en: http://www.expreso.ec/guayaquil/la-reubicacion-de-familias-junto-al-esterono-avanza-y-estas-siguen-descargando-DJ139533

${ }^{37}$ Arq. Anabella Roitman

${ }^{38}$ Arq. Cecilia Santiago

${ }^{39}$ Andrés Vecchio 
I. Carácter de la intervención

II. Estrategia propuesta

III. Actores intervinientes y afectados

IV. Concepción del Espacio Publico considerada

V. Capacidad/ poder de integración del proyecto a su entorno/ de los vecinos a la ciudad

VI. Relación entre las políticas habitacionales y las políticas de Espacio Publico

Ilustración 5: Tabla síntesis de los casos analizados - Reurbanización Villa 20 - Jardín Circunvalar - Parque Lineal Suburbio

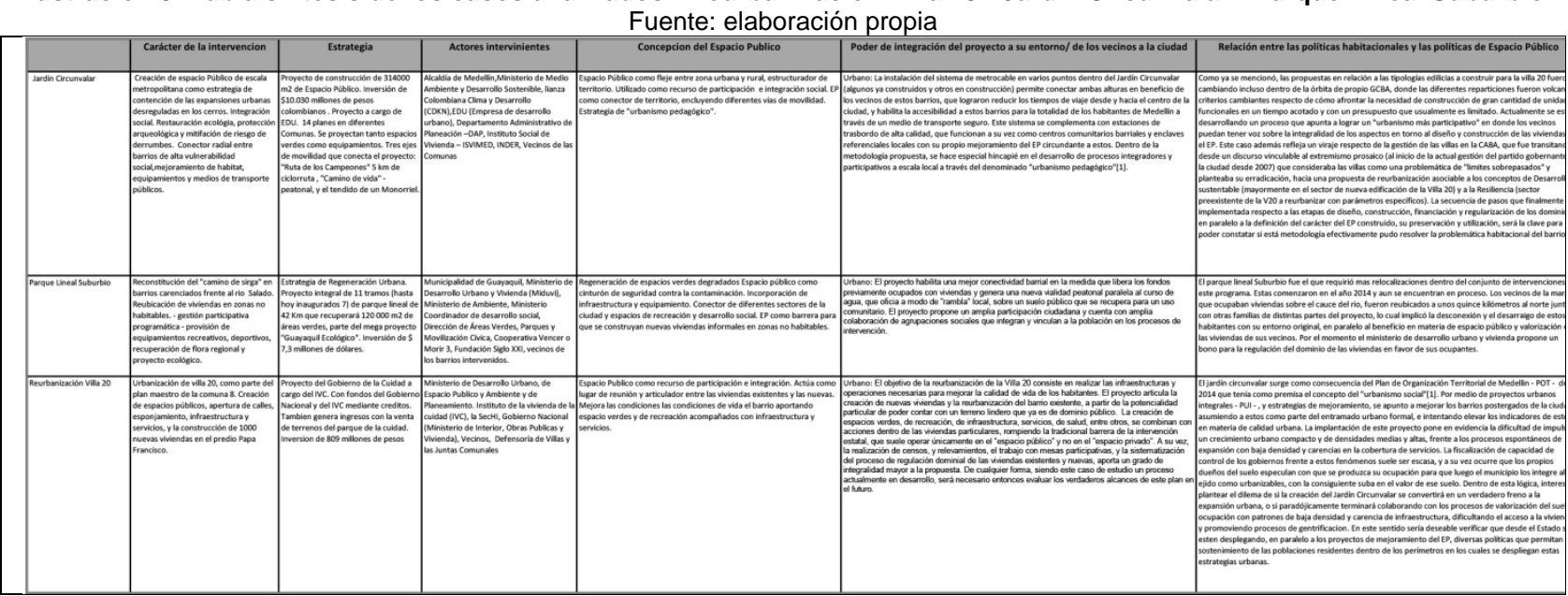

Como fuente de información se realizó trabajo de campo en las tres ciudades durante los años 2016 y 2017. Se relevaron publicaciones en medios de comunicación masivos, en los portales web de cada municipio, y en otros medios locales alternativos, y se realizaron entrevistas con actores específicos.

A partir de estos insumos, se realizó una breve descripción de cada caso, en vías de contrastar las diferentes actuaciones respecto de las políticas de espacio público - PEP- desplegadas sobre suelo público, e impulsadas en cada ciudad.

\section{Presentación de los casos de estudio}

A continuación se presentan los 3 casos estudiados:

\subsection{Caso n`1 - Reurbanización de la Villa 20 - Comuna 8 - Buenos Aires - Argentina.}

Esta villa miseria data de 1970 y posee una población en fuerte crecimiento, con un alto nivel de verticalización (edificios de hasta cinco pisos). En 2010 la población era de casi a 20.000 personas, y para 2013 la ONG Techo estimaba la población en 60 mil personas.( info diario Clarín - 2015) Sin embargo, otros medios indican que en la villa 20 de Lugano viven 28.000 personas: unas 9200 familias en 4500 viviendas (diario La Nación - 2017).

En 2014 la villa estuvo en el foco de los medios por la toma de un terreno lindero que había sido liberado para su saneamiento, pero sin avance de obras. Se produjo entonces la ocupación del predio por un gran número de vecinos (aprox. 1200 personas) que construyeron el entonces denominado Barrio "Papa Francisco". Este asentamiento fue desalojado 6 meses después por el GCBA. Después del desalojo, la jueza Elena Liberatori ordenó la urbanización de la Villa 20, y se aprobó en 2016 la ley de "reurbanización, zonificación e integración socio-urbana de la villa 20" (en el marco de la Ley 1770 del año 2005, que ya ordenaba oportunamente la urbanización del predio).

\subsubsection{Carácter de la intervención:}

Se propone la urbanización de predio lindero a la actual Villa 20 y Re-urbanización del tejido barrial existente. 


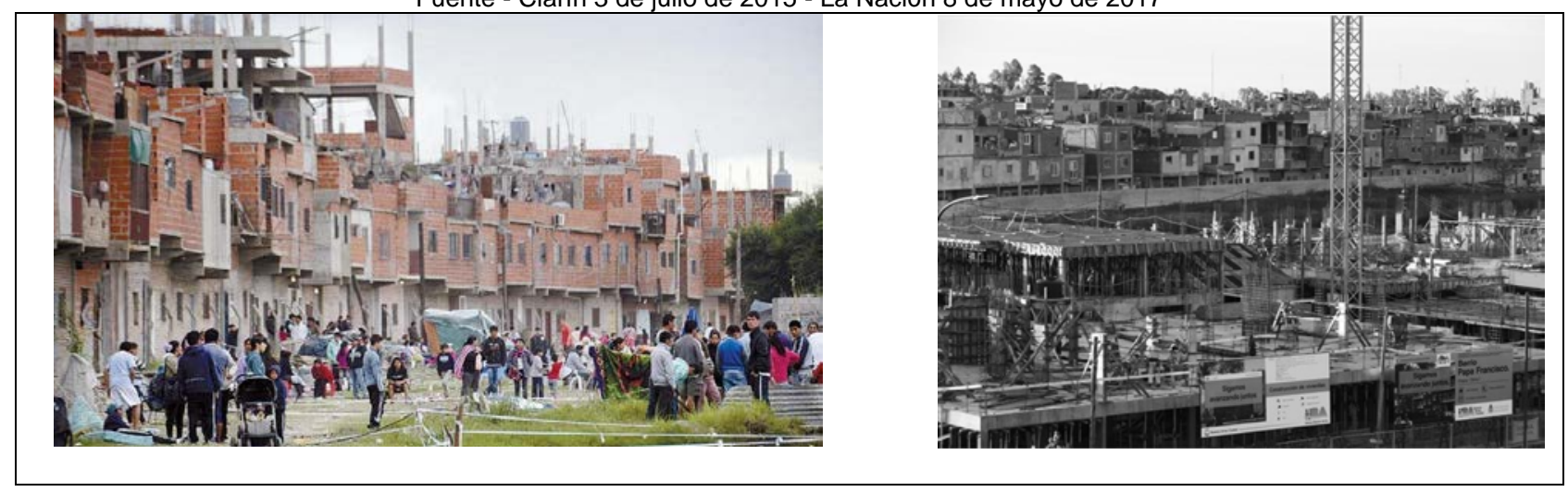

\subsubsection{Estrategia propuesta:}

Para la realización de este proyecto, el instituto de la vivienda de la ciudad - IVC diseñó durante 2016 un "Proyecto Integral de Reurbanización" - PIRU. Según las publicaciones consultadas, esta metodología propone el trabajo a través de la planificación por proyecto - proceso, en la cual se apunta a lograr un producto - meta más flexible y consensuable, en lugar de apuntar a un producto predefinido y "cerrado" 40 . Como parte de esta estrategia se realizó un censo poblacional y de unidades habitacionales, junto con el saneamiento ambiental del predio lindero a la villa. Actualmente estarían en construcción unas 500 de las 1500 viviendas proyectadas ( 9 edificios en total) junto con sus respectivas redes de servicios, calles y espacios públicos. El proyecto incluiría algunos equipamientos públicos (Escuelas, centros de salud, y capacitación laboral, entre otros)y en una segunda etapa se realizarían las aperturas de calles en tejido existente y la respectiva expansión de redes, que incluiría además la refacción de 4600 viviendas para su respectiva regularización dominial.

Previamente a este proceso, en 2015, se organizó un concurso de proyectos de arquitectura para el diseño de los conjuntos de viviendas, a realizarse en 4 etapas que a su vez coincidían con diferentes sectores del masterplan propuesto por el área de planeamiento del GCBA. Este concurso fue cancelado en la mitad de su proceso de ejecución, a inicios del 2016, habiendo seleccionado ya a los ganadores de las primeras 2 etapas, los cuales finalmente fueron incorporados a un equipo que en la actualidad participa en la revisión y adecuación de las propuestas ganadoras junto con el Instituto de la Vivienda de la Ciudad - IVC. A su vez, el IVC estaría trabajando en el ajuste del masterplan y definición tipológica de las nuevas viviendas, en base a un trabajo participativo realizado por el Taller Libre de Proyecto Social - TLPC de la FADU - UBA.

\subsubsection{Actores intervinientes:}

Para este proyecto articulan por una parte la Ssec. de Hábitat e Inclusión -SSECHI, el Instituto de la Vivienda de la Ciudad - IVC, la Corporación del Sur - CBASSE, y los ministerios de Desarrollo Urbano, MDUyT Desarrollo Social - MDS - de GCBA, junto con la Mesa x la Urbanización de la Villa 20, las ongs vinculadas a la temática (ej. ACIJ), los delegados barriales, la Sociedad Central de Arquitectos - SCA , la Defensoría del pueblo de CABA y el Taller Libre de Proyecto Social de la FADU.

\footnotetext{
${ }^{40}$ Para más información sobre la gestión de este proyecto ver: "Gestión y planificación por proceso - proyecto para el mejoramiento de villas y asentamientos de gran escala. El caso de la Re-Urbanización de Villa 20 en la CABA". Autores: Motta, Jorge Martín y Almansi, Florencia, 2016.
} 
Ilustración 7: Alternativas de masterplan - Concurso 1000 viviendas - GCBA - y Taller Libre de proyecto Social - 2015. Fuentes: WEB TLPC y GCBA

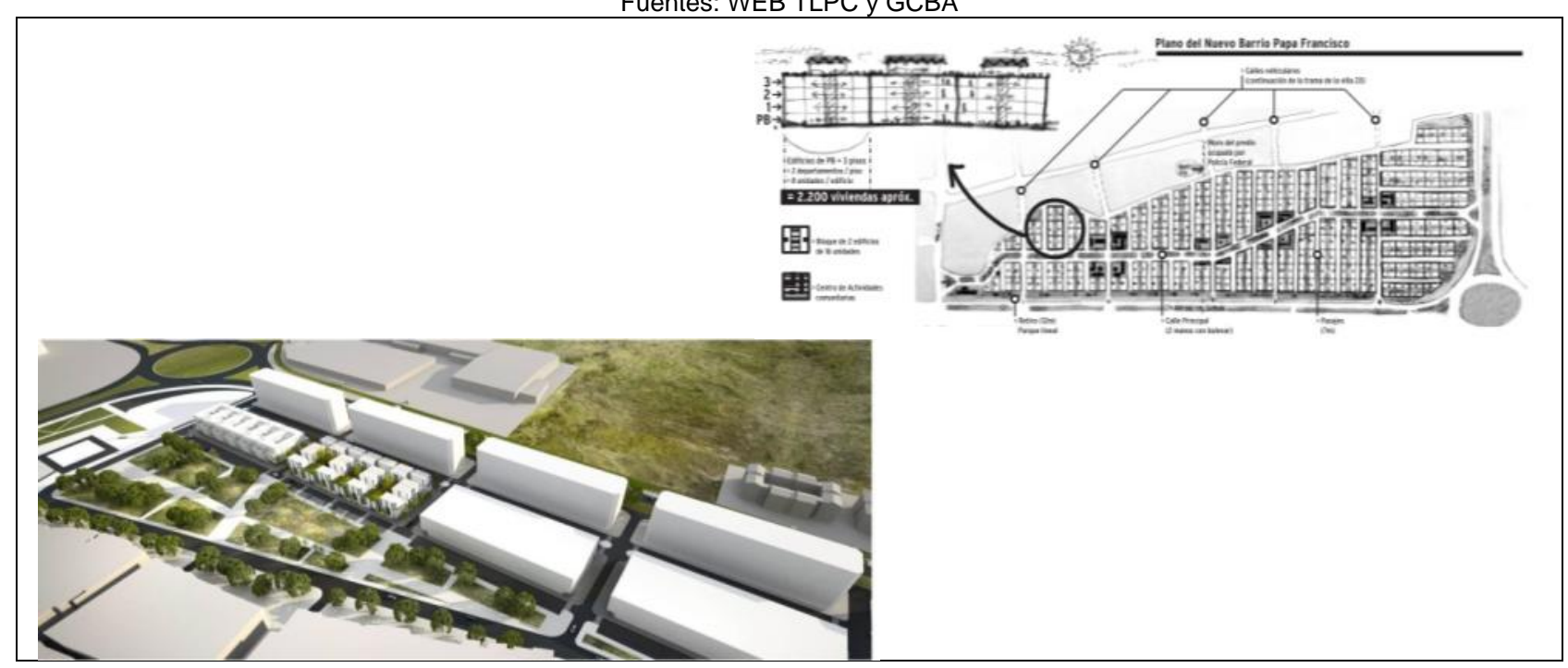

\subsubsection{Concepción del Espacio Público:}

Este proyecto tuvo diferentes concepciones acerca del rol del EP a medida que se sucedieron las distinas propuestas presentadas, tanto desde el poder ejecutivo del GCBA (Ministerio de Desarrollo Urbano - MDU), como las opciones alternativas consensuadas con vecinos a través del asesoramiento del TLPC, y los recambios de autoridades dentro del IVC entre 2015 y 2017.

Respecto a los concursos realizados, estos proponían formas de ocupar los amazanamientos predefinidos por la base parcelaria diseñada por el MDU, en la cual un gran parque en forma de cuña mediaba entre la preexistencia y lo nueva urbanización. En este concurso, todo el Masterplan, incluido el EP principal, fue previsto con anterioridad y no se incluyó como ítem en las bases de este. Los concursantes de todas formas incluyeron espacios semipúblicos previstos en los patios, boulevares pasantes y en las terrazas de las viviendas sociales.

Recientemente hubo alguna difusión en los medios de comunicación en relación al masterplan definitivo. Este resultaría un hibrido entre los avances de 3 gestiones intervinientes, donde se combinarían 2 tipologías diferentes de viviendas: las seleccionadas por el equipo del IVC 2015 - 2016 (fuera del concurso) y las aprobadas por el equipo actual, (ajustando las propuestas ganadoras de los concursos de 2015).

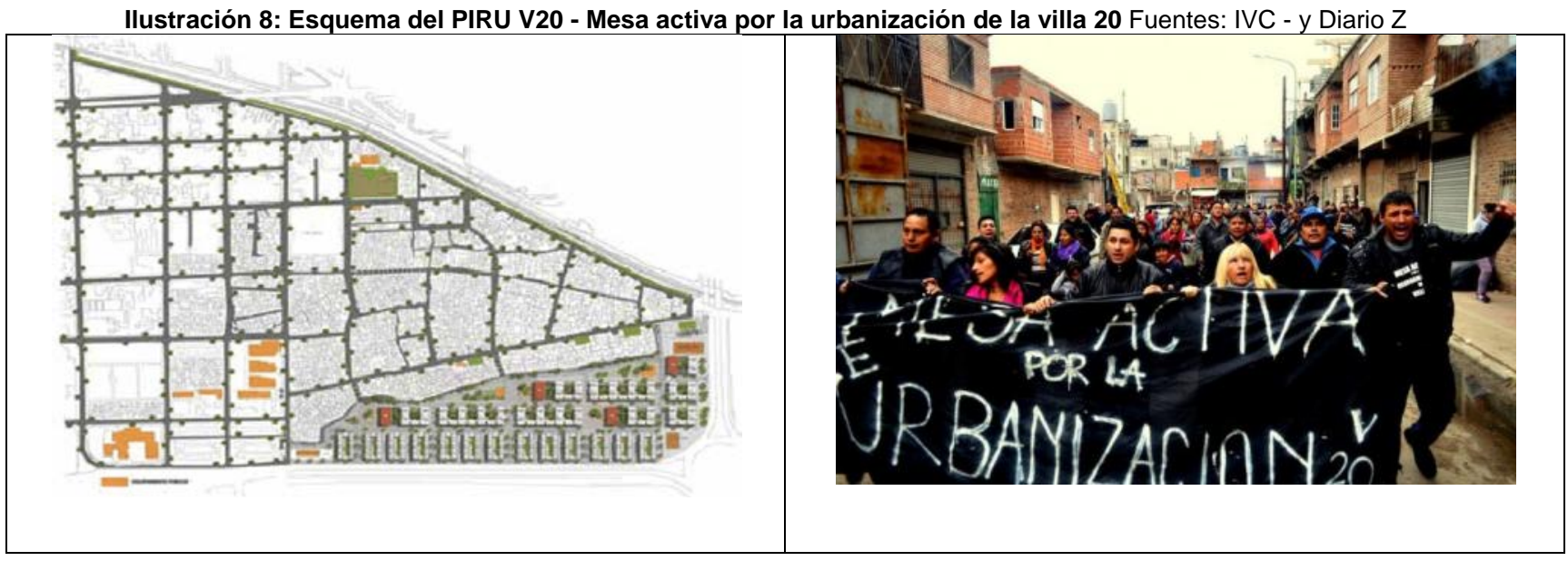

\subsubsection{Capacidad/ poder de integración del proyecto a su entorno/ de los vecinos a la ciudad}

Urbano: El proyecto articula la creación de nuevas viviendas y la reurbanización del barrio existente, a partir de la potencialidad particular de poder contar con un terreno lindero que ya es de dominio público.

La creación de espacios verdes, de recreación, de infraestructura, servicios, de salud, entre otros, se combinan con acciones dentro de las viviendas particulares, rompiendo la tradicional barrera de la intervención estatal, que suele operar únicamente en el "espacio público" y no en el "espacio privado". 
A su vez, la realización de censos, y relevamientos, el trabajo con mesas participativas, y la sistematización del proceso de regulación dominial de las viviendas existentes y nuevas en el marco de una secuencia lógica donde prime la radicación definitiva, aporta un grado de integralidad mayor a la propuesta.

De cualquier forma, siendo este caso de estudio un proceso actualmente en desarrollo, será necesario entonces evaluar los verdaderos alcances de este plan en el futuro.

Ambiental: A partir de la remediación ambiental del predio lindero, la instalación de desagües pluviales que eviten las habituales inundaciones en el barrio, la creación de nuevo suelo absorbente y el esponjamiento de la actual trama barrial, es posible que puedan detectarse mejoras en los indicadores en materia ambiental, que a su vez impactarán positivamente en la salud de los habitantes, considerando que actualmente el acceso a las viviendas en la Villa 20 se da a través de angostos pasillos en el $55 \%$ de los $\operatorname{casos}^{41}$. Sin embargo, interesa mencionar que parte de la financiación para la urbanización de esta villa provendría a su vez, de la urbanización del predio vecino dentro del Parque de la Ciudad, que redujo su superficie absorbente para habilitar la construcción de 15 edificios de propiedad horizontal (la denominada "villa Olímpica").

Como punto a favor, frente a la situación de parálisis crónica de obras bajo el argumento de la existencia de pasivos ambientales (más allá de la existencia de una ley de urbanización desde 2005), actualmente se procedió al saneamiento ambiental del predio lindero a la villa, y está en marcha la construcción de viviendas en este sector, como parte del proceso de reurbanización.

Infraestructura y Servicios: La realización de las obras de infraestructura, que son las que necesariamente el Estado debe afrontar porque exceden la capacidad individual de cada vecino, significan además en este caso una acción fundamental, en el marco de la preexistencia de un Plan Urbano para la totalidad de la Comuna 8 (Plan Maestro Comuna 8 de 2011) donde esta y otras villas ya se encuentran debidamente caracterizadas y a la espera de sus respectivas obras de saneamiento para lograr la integración de estas a los demás barrios comunales.

\subsubsection{Relación entre las políticas habitacionales y las políticas de Espacio Público}

Las propuestas para las nuevas las tipologías edilicias a construir para la Villa 20, y su relacion con el EP fueron mutando dentro de la órbita de propio GCBA, donde las diferentes reparticiones fueron volcando sus criterios respecto de cómo afrontar la construcción de gran cantidad de unidades funcionales en un tiempo acotado y con un presupuesto limitado. En la versión del proyecto de MDU en 2015, las viviendas se alojaban en bloques compactos sobre la avenida, mientras el EP oficiaba de fuelle "integrador" entre la preexistencia y estos nuevos edificios. El proyecto actual por su parte, combina las tipologías definidas por la gestión 2016 del IVC, de planta baja +3 pisos, con calles peatonales y vehiculares, donde el EP no tendría un rol preponderante mas allá de su aporte funcionalista de habilitar la circulación y acceso a las viviendas. Finalmente las propuestas aggiornadas en base a los fallidos concursos de ideas realizados, proponen una reflexión sobre el EP que se distribuye en forma de plazas pequeñas y de patios y terrazas dentro de cada bloque de vivienda.

La secuencia de pasos que finalmente sea implementada respecto a las etapas de diseño, construcción, financiación y regularización de los dominios, en paralelo a la definición del carácter del EP construido, su preservación y utilización, será la clave para poder constatar si la metodología del PIRU V20 efectivamente pudo resolver la problemática habitacional del barrio.

${ }^{41}$ Ídem Cita (informe villa 20 - IVC). 
llustración 9: Título imágenes: Situación de la villa 20 al interior de esta, y avance de obra de las nuevas viviendas - julio 2017.

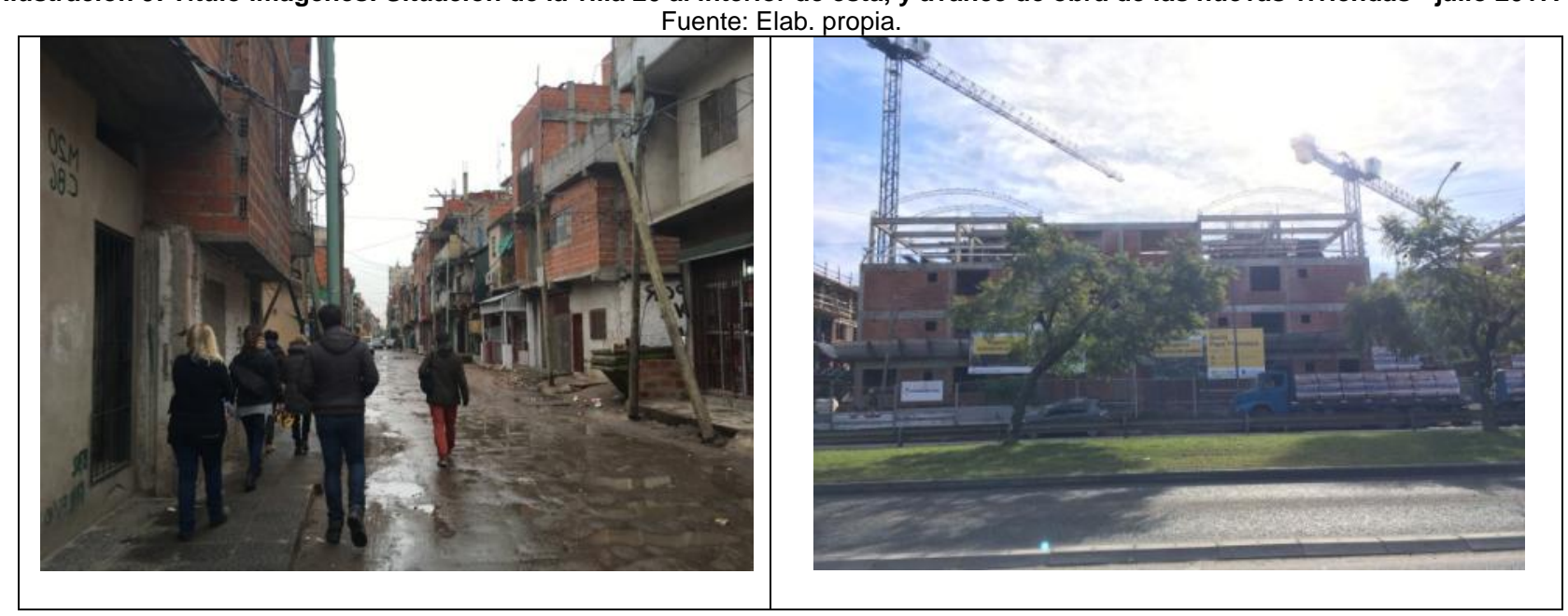

\subsection{Caso $\mathrm{n}^{\circ} 2$ - Parque Lineal Suburbio. Guayaquil. Ecuador}

La ciudad de Guayaquil tiene una población equivalente al 17\% del total del país. Los estratos medios y bajos son los que mayor tasa de crecimiento tienen ${ }^{42}$. El crecimiento desordenado y espontaneo de las áreas urbanas, hace que los asentamientos ocupen zonas especiales protegidas como los esteros y manglares, que repercuten además en forma negativa a nivel ambiental.

En este sentido, estudios realizados demuestran que los índices de espacio verde por habitante de la ciudad se encontraban muy por debajo de los estándares deseables, a la vez que se demostraba que el mayor problema de la contaminación del estero sería de origen doméstico ${ }^{43}$. En junio del 2013 se presenta el proyecto "Guayaquil Ecológico" que propone la regeneración y restauración de áreas verdes, a través de la creación de 11 tramos con un total de $41 \mathrm{~km}$ de parques lineales.

\subsubsection{Carácter de la intervención:}

Consistió en el saneamiento ambiental del sector, la construcción de parques lineales en la costa del Rio Salado y la reubicación de las familias asentadas en los bordes que constituían "áreas críticas".

\subsubsection{Estrategia propuesta:}

Se propuso una estrategia de Regeneración Urbana ${ }^{44}$ bajo el nombre "Guayaquil Ecológico ${ }^{45 ", ~ u n ~ p r o y e c t o ~}$ integral de intervención en diferentes tramos del Rio salado. La operación incluye la creación de un parque lineal de $42 \mathrm{~km}$ de extensión (120.000 m2 de áreas verdes) con el objetivo de mejorar las condiciones habitacionales de los pobladores y de sanear el Rio Salado.

Se plantea la recuperación y el mantenimiento de la cobertura vegetal, la gestión de residuos, educación ambiental, reubicación de viviendas en zonas no habitables, entre otros. A esto se lo acompaña con el desarrollo de infraestructura y equipamientos para la población que van desde agua potable, cloacas, alumbrado público y espacios de recreación, entre otros.

\footnotetext{
42 Ver Núñez - 2013.

${ }^{43}$ La Dirección de Áreas Verdes y Movilización Cívica indica que en el año 2000 existían en la ciudad de Guayaquil 551 has. de superficie de áreas verdes, con un índice de 2.75 m2/hab., mucho menos de los 8 a $15 \mathrm{~m} 2 / \mathrm{hab}$. que recomienda la O.M.S.

${ }^{44}$ El término Regeneración Urbana Integral se define como tal en la Declaración de Toledo de 2010 como "la consecución de un desarrollo urbano más inteligente, sostenible y socialmente inclusivo". Fuente: "Que es el regeneración urbana integral" publicado en el sitio web "La Ciudad viva". Disponible en: http://www.laciudadviva.org/blogs/?p=19123

${ }^{45}$ El Proyecto Guayaquil Ecológico tiene como finalidad incrementar las áreas verdes en la ciudad y generar espacios recreativos. El proyecto se enfoca sobre tres componentes que son: Parque Samanes / Isla Santay I. Estero Salado. Este último se trabaja desde el Ministerio de Desarrollo Urbano y Vivienda en coordinación con otras Instituciones. Actualmente se está realizando la limpieza de las orillas y se espera intervenir con una construcción de $41 \mathrm{Km}$ de parques lineales a lo largo de 11 tramos. Info. extraída del sitio web. disponible en: https://www.facebook.com/GyeEcologico
} 
llustración 10: Villa 20 - Situación previa del cauce natural del Rio Salado. Viviendas asentadas en el borde de la rivera. Fuente - Articulo 2012 Norwegian Institute for Water Research.

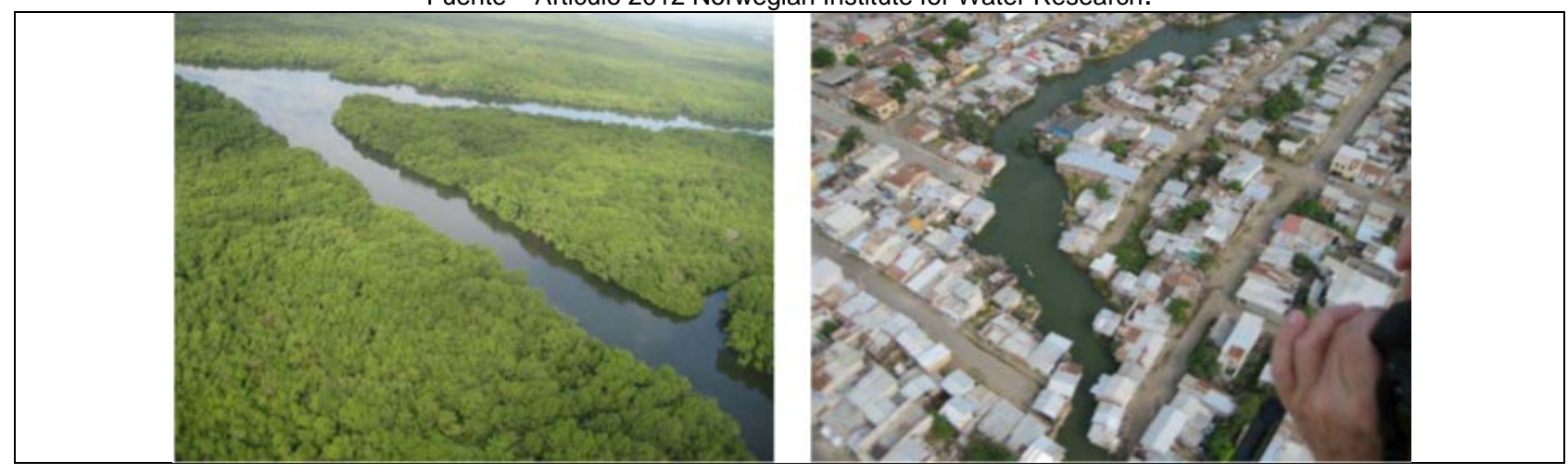

\subsubsection{Actores intervinientes:}

Los actores intervinientes fueron: el Ministerio de Desarrollo Urbano y Vivienda de la nación (Miduvi), el Ministerio de Ambiente de la nación, el Ministerio Coordinador de desarrollo social de la nación, la Dirección de Áreas Verdes, Parques y Movilización Cívica, la Cooperativa Vencer o Morir 3, la Fundación Siglo XXI, y los vecinos de los barrios intervenidos.

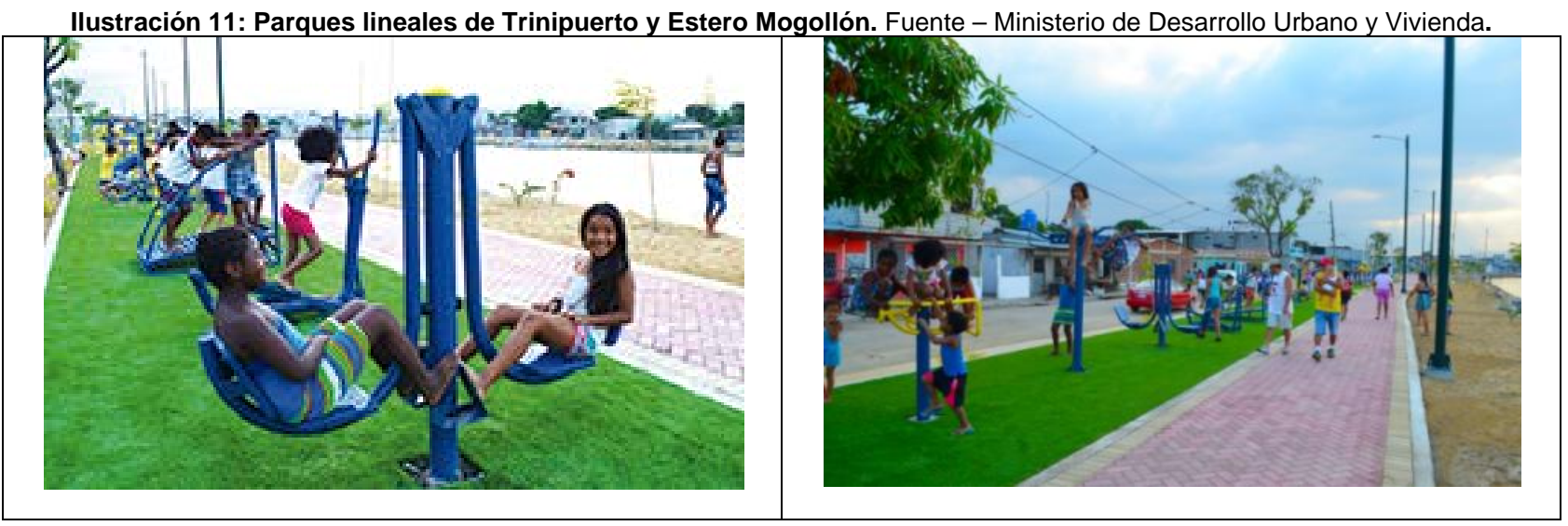

\subsubsection{Concepción del Espacio Público:}

En este caso, el EP operaría como una suerte de "cinturón de seguridad" contra la generación de áreas criticas: viviendas asentadas sobre suelos inundables y/o contaminados. A su vez, esta estrategia permitiría la incorporación de equipamiento público para barrios alejados de las centralidades, para mejorar sus estándares en materia de accesibilidad a áreas parquizadas, arboladas e iluminadas, acceso a juegos infantiles, estaciones aeróbicas, bicisendas y mobiliario urbano, como parte de la generación de nuevo espacio recreativo y comunitario para los barrios y a escala urbana. 
llustración 12: fotografías del proyecto - Parque Lineal Suburbio - Octubre 2016 - Fuente: elaboración propia.

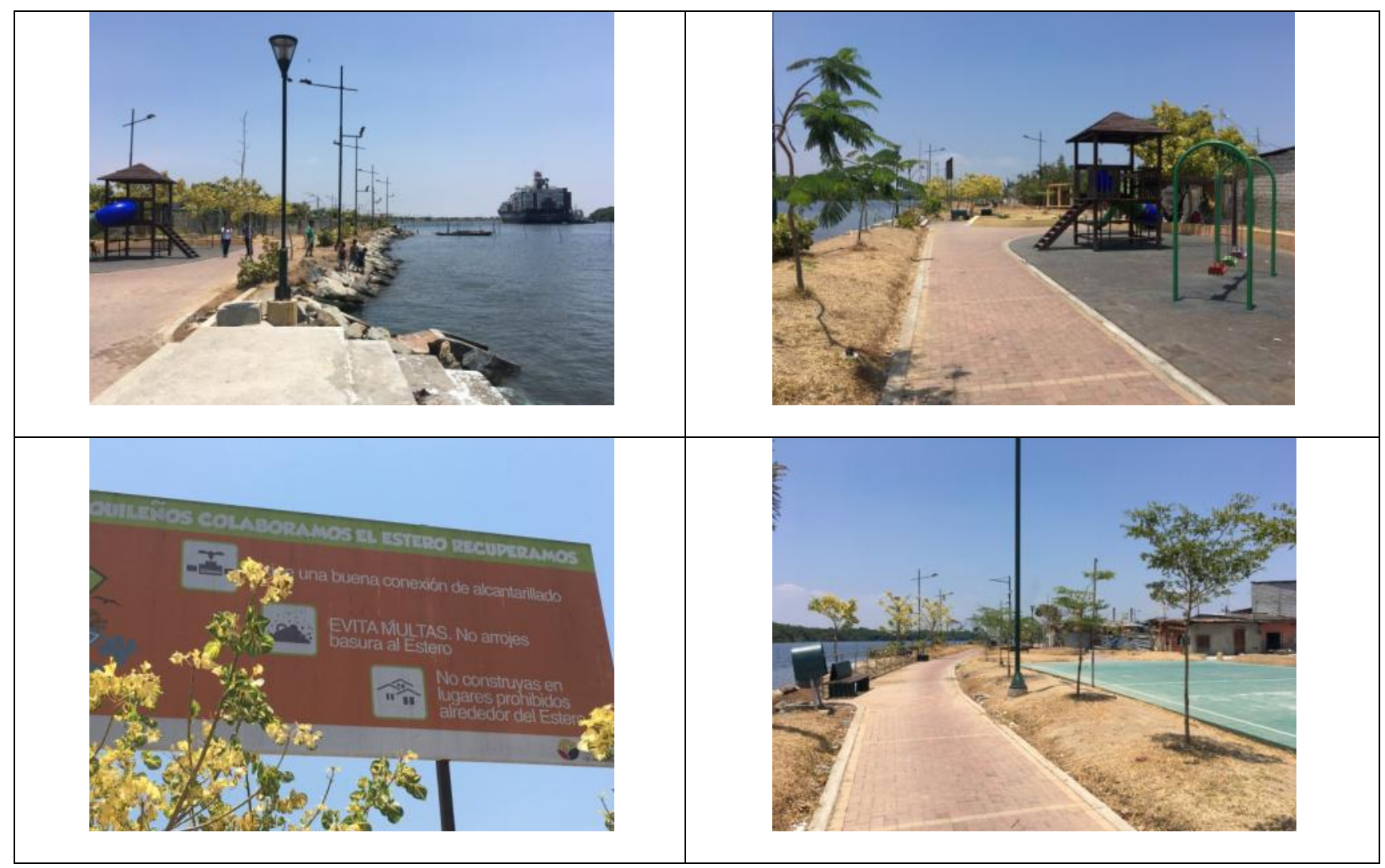

\subsubsection{Capacidad/ poder de integración del proyecto a su entorno/ de los vecinos a la ciudad}

Urbano: El proyecto habilita una mejor conectividad barrial en la medida que libera los fondos previamente ocupados con viviendas y genera una nueva vialidad peatonal paralela al curso de agua, que oficia a modo de "rambla" local, sobre un suelo público que se recupera para un uso comunitario. El proyecto propone un amplia participación ciudadana y cuenta con la colaboración de agrupaciones sociales que integran y vinculan a la población en los procesos de intervención.

Ambiental: El principal aporte en materia ambiental es el saneamiento de las márgenes del rio Salado. El control de los desechos industriales permitió que el rio mejore sus indicadores en materia de contaminación del agua, y las mejoras en las condiciones de vida de los habitantes. La creación de un parque lineal permitió además la recuperación de la fauna y la flora nativas. Sin embargo, el estado actual de algunos sectores del parque demuestra las limitantes en relación al mantenimiento del mismo (tareas de limpieza, riego, mantenimiento, etc.) que atentan contra su potencialidad como remediador ambiental.

Infraestructura y Servicios: En este caso el proyecto contempla, además del equipamiento urbano, obras de desagües pluviales y alcantarillado como parte de la estrategia para el correcto saneamiento del sector.

\subsubsection{Relación entre las políticas habitacionales y las políticas de Espacio Público}

El Parque Lineal Suburbio fue el que requirió mas relocalizaciones dentro del conjunto de intervenciones de este programa. Los vecinos de la margen que ocupaban viviendas sobre el cauce del rio, fueron reubicados junto con otras familias, fuera del radio del proyecto, lo cual implicó la desconexión y el desarraigo de estos habitantes con su entorno original, en paralelo al beneficio en materia de espacio público y valorización de las viviendas de sus vecinos que pudieron mantener sus localizaciones originales.

\subsection{Caso $n^{\circ} 3$ - Jardín Circunvalar - Medellín - Colombia}


Debido a los conflictos armados vinculados a la guerrilla y el narcotráfico que generan desplazamientos del campo a los centros urbanos, y gracias al desarrollo industrial de Colombia, sus ciudades comienzan a crecer y a expandirse con mas velocidad a partir de 1940. "Bajo estas condiciones, se da inicio a un proceso de ocupación y transformación de las laderas de la ciudad, ubicadas en los límites con las zonas rurales que rodean a la capital antioqueña; en el caso de la comuna 8, durante la década del 70 y 80 del siglo XX, comienzan a construirse sectores de invasión en la parte alta de la comuna" (Chancy Brun: 2015).

Para contener la expansión de la ciudad, se plantea la construcción de un "Cinturón verde metropolitano", en el marco del Plan de Desarrollo 2012-2015: "Medellín, un Hogar Para la Vida", que se enmarca a su vez en el Plan de Ordenamiento de la Ciudad - POT de 2006, desde el cual se busca lograr una compactación de la trama urbana, y la racionalización del uso y ocupación del suelo.

\subsubsection{Carácter de la intervención:}

Creación de EP de escala metropolitana como estrategia de contención de las expansiones urbanas desreguladas en los cerros. Proyecto de integración social, ecológica, conectividad vertical y longitudinal, protección arqueológica y mitigación del riego de derrumbes.

\subsubsection{Estrategia propuesta:}

Construcción de $314.000 \mathrm{~m} 2$ de EP, en donde se proyectan tanto espacios verdes como equipamientos, infraestructura y servicios. Se plantean cinco ejes a resolver: el control de la expansión urbana, el acceso a la vivienda digna, la generación de espacios público como estructurador del territorio, la sostenibilidad del territorio y la conectividad de este con las áreas centrales de la ciudad.

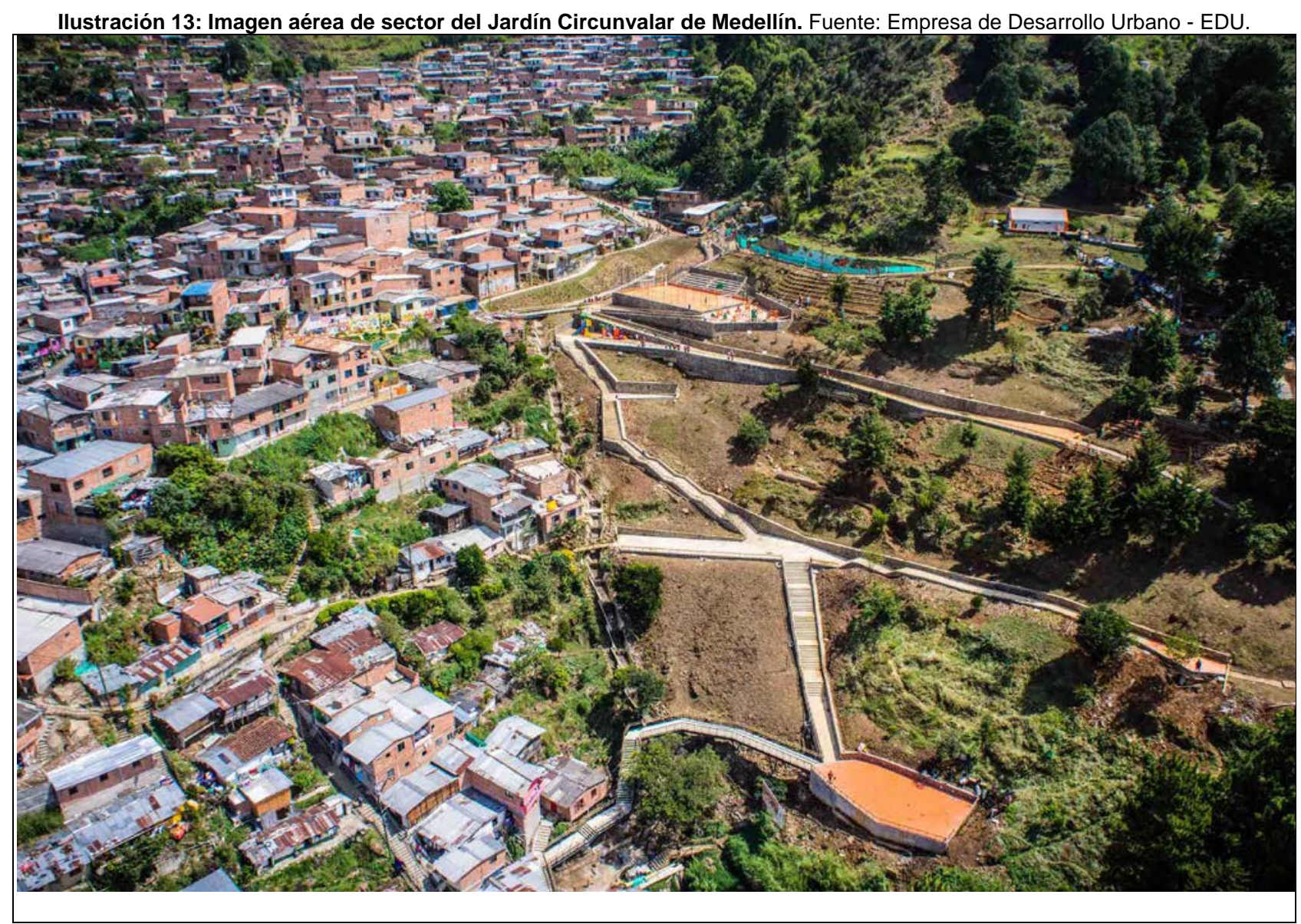

\subsubsection{Actores intervinientes:}

Los actores intervinientes son: La Alcaldía de Medellín, el Ministerio de Medio Ambiente y Desarrollo Sostenible, la alianza Colombiana Clima y Desarrollo (CDKN), la E.D.U. (Empresa de desarrollo urbano), 
Departamento Administrativo de Planeación -DAP, Instituto Social de Vivienda - ISVIMED, INDER, Vecinos de las Comunas.

\subsubsection{Concepción del Espacio Público:}

En este caso el EP opera como fuelle natural y barrera estratégica entre zona urbana y rural en sentido "abajo" (el centro urbano consolidado y con servicios) - "arriba" (la periferia en expansión y sin servicios). A nivel longitudinal este proyecto de EP funciona como conector entre los diferentes barrios ubicados sobre los cerros, al habilitar una continuidad de circulación peatonal y en bicicleta entre sectores de ciudad previamente desvinculados.

A escala metropolitana el Jardín Circunvalar, por sus dimensiones, constituye un nuevo parque urbano en altura, de alta calidad, que revierte parcialmente el tradicional rol de "patio trasero" de los bordes periurbanos a la vez que anula la posible especulación inmobiliaria, al retirar estos predios del mercado inmobiliario.

Ilustración 14: Imagen de senderos peatonales y aula educativa - Pieza grafica de presentación del proyecto. Fuentes: Elaboración propia - junio 2017 - Alcaldía de Medellín + EDU

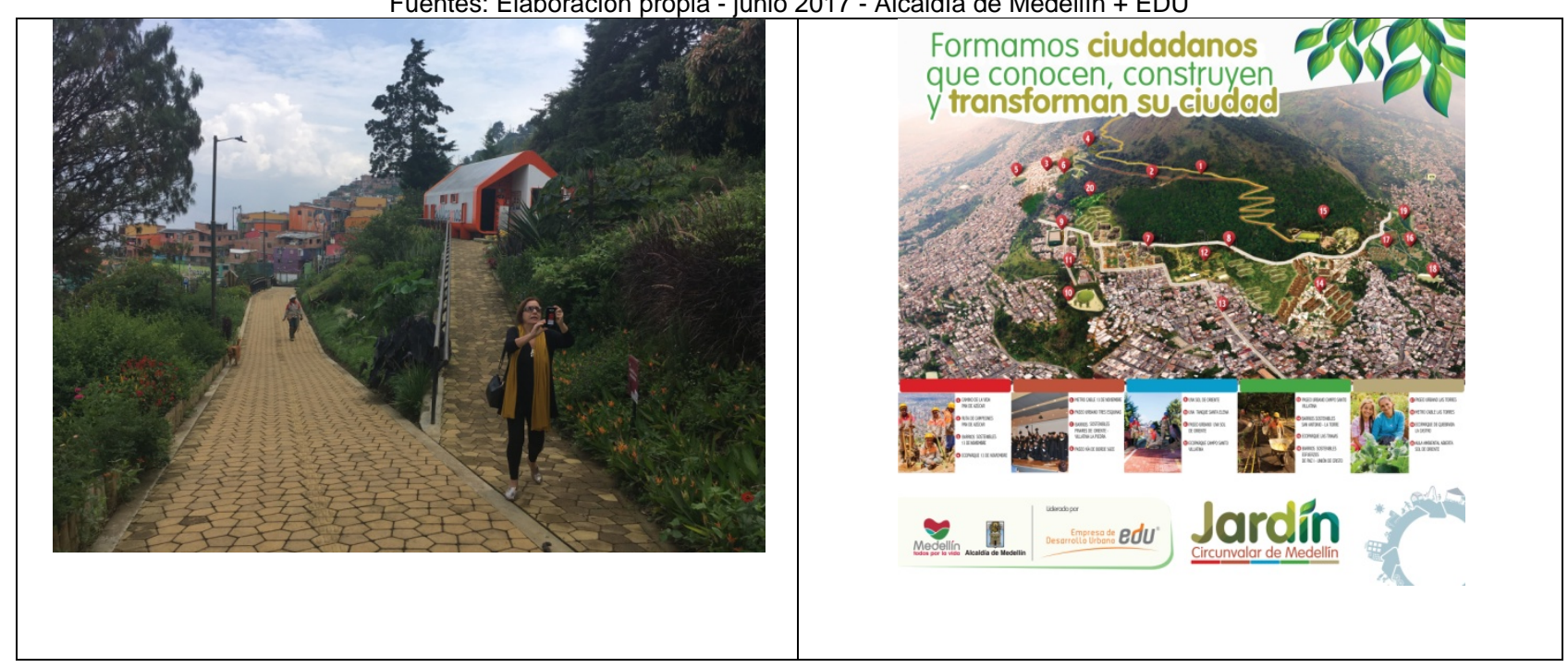

\subsubsection{Capacidad/ poder de integración del proyecto a su entornol de los vecinos a la ciudad}

Urbano: La instalación del sistema de metrocable en varios puntos dentro del Jardín Circunvalar (algunos ya construidos y otros en construcción) permite conectar ambas alturas en beneficio de los vecinos de estos barrios, (que lograron reducir significativamente los tiempos de viaje desde y hacia el centro de la ciudad), y habilita la accesibilidad a estos barrios para la totalidad de los habitantes de Medellín a través de un medio de transporte seguro.

Este sistema se complementa con estaciones de trasbordo de alta calidad, que funcionan a su vez como centros comunitarios barriales y enclaves referenciales locales con su propio mejoramiento del EP circundante a estos. Dentro de la metodología propuesta, se hace especial hincapié en el desarrollo de procesos integradores y participativos a escala local a través del denominado "Urbanismo Pedagógico"46.

Ambiental: El proyecto propone educar en materia ambiental a través de la instalación de aulas especiales donde se dictan capacitaciones. A su vez, la creación de huertas comunitarias dentro del predio, permite a la población local obtener cierto nivel de autoabastecimiento y comercialización de alimentos como fuentes alternativas de ingresos. En paralelo, la construcción de canales de riego y obras de fijación de las laderas, lograron efectivamente disminuir los derrumbes de estas áreas.

Infraestructura y Servicios: La dotación a escala metropolitana de servicios urbanos tales como la creación de un nuevo parque, la construcción de bicisendas y senderos peatonales iluminados y equipados, impactaron positivamente en las vidas tanto de los vecinos de los barrios cercanos, (que participaron del diseño y la

46 "El termino urbanismo pedagógico es un término desarrollado en Medellín por el cual los ciudadanos aprenden en toda la ciudad. La ciudad es educadora, sus espacios públicos, la calle y los parques". Fuente: "¿Qué es el urbanismo pedagógico?" Publicado en el sitio web de la Corporación andina de Fomento - CAF. Disponible en: https://www.caf.com/es/actualidad/noticias/2015/09/que-es-el-urbanismo-pedagogico/ 
construcción de estos), como de la totalidad de la población de Medellín que amplió sus posibilidades de acceso a espacios verdes públicos. Sin embargo, los altos costos de construcción y mantenimiento de este proyecto y los subproyectos asociados significara la necesidad del sostenimiento en el largo plazo de las políticas públicas que permitan dar continuidad a los medios de financiación de estos.

\subsubsection{Relación entre las políticas habitacionales y las políticas de Espacio Publico}

El jardín circunvalar surge como consecuencia del Plan de Organización Territorial de Medellin - POT - que tenía como premisa el concepto del "urbanismo social"47. Por medio de proyectos urbanos integrales - PUI -, y estrategias de mejoramiento, se apuntó a mejorar los barrios postergados de la ciudad, asumiendo a estos como parte del entramado urbano formal, e intentando elevar los indicadores de estos en materia de calidad urbana.

La implantación de este proyecto pone en evidencia la dificultad de impulsar un crecimiento urbano compacto y de densidades medias y altas, frente a los procesos espontáneos de expansión con baja densidad y carencias en la cobertura de servicios. La capacidad de control de los gobiernos frente a estos fenómenos suele ser escasa, sumado a los procesos especulativos que se generan en los bordes periurbanos, donde los propios dueños del suelo especulan con que se produzca su ocupación para que luego el municipio los integre al ejido como urbanizables, con la consiguiente suba en el valor de ese suelo. Dentro de esta lógica, interesa plantear el dilema de si la creación del Jardín Circunvalar se convertirá en un verdadero freno a la expansión urbana, o si paradójicamente terminará colaborando con los procesos de valorización del suelo y ocupación con patrones de baja densidad y carencia de infraestructura, dificultando el acceso a la vivienda y promoviendo procesos de gentrificacion. En este sentido sería deseable verificar que desde el Estado se estén desplegando, en paralelo a los proyectos de mejoramiento del EP, diversas políticas que permitan el sostenimiento de las poblaciones residentes dentro de los perímetros en los cuales se despliegan estas estrategias urbanas.

\section{Conclusiones}

Consecuentemente, y a juzgar por los casos vistos, el ejercicio de "desnaturalización" del concepto de EP resulta un paso previo necesario para permitirse repensar el rol que juega actualmente, reconstruirlo y contrastarlo con los actuales criterios de producción y gestión urbanística, los discursos y los paradigmas asociables a la gestión ambiental imbricados en estos.

Respecto a la generación de nuevo EP, se observan múltiples objetivos para la actuación en suelo público. El EP entonces va tomando diversos roles en cada caso:

- La preservación y adecuación de áreas periurbanas con fines de contención de la mancha urbana (Jardín Circunvalar)

- La re-urbanización y ampliación de un barrio preeexistente, a través de tareas de remediación ambiental del suelo, la provisión de infraestructura, equipamiento y servicios, y construcción de nuevas viviendas colectivas (Villa 20)

- La recuperación de los bordes costeros como espacios públicos comunitarios de acceso pleno a los cursos de agua (Parque Lineal suburbio).

Estos roles funcionales permiten plantear diferentes definiciones de EP, que amplían su caracterización como instrumento o dispositivo de gestión urbana. La creación de EP entonces no sería solo un servicio urbano, sino que este oficia de medio para el impulso de operatorias de mas complejidad.

En esta línea, dentro de la retórica discursiva recurrente en la gestión publica a la hora de impulsar proyectos, se destaca habitualmente la creación de nuevo EP "para los vecinos", lo cual genera desconfianza en algunos actores sociales que consideran esta afirmación como un modo de ocultar la consiguiente pérdida de suelo público "en manos de desarrolladores privados en alianza con el Estado".

Sin embargo, para los tres casos estudiados, la generación de EP operaría efectivamente como aporte positivo a las comunidades, en la medida que oficia como recurso de articulación entre áreas ambientales a

47 "El urbanismo social es el componente más impactante. Consiste, básicamente, en el direccionamiento de grandes inversiones en proyectos urbanísticos puntuales hacia los sectores populares de la ciudad. Argumentando que la ciudad tiene una deuda histórica con estos sectores olvidados, se ha apostado a cancelarla mediante la construcción de obras infraestructurales y arquitectónicas de alta calidad y fuerte impacto tanto estético como social". BRAND (2010) 
preservar a escala regional, entornos preexistentes a integrar y conectar a escala urbana, y barrios carenciados a urbanizar.

Vinculado a este concepto, sobre a la cuestión del "EP como representación de Lo cívico y Lo popular" versus el espacio privado, asumido como "individual", es posible ver en algunos de estos proyectos una trascendencia de esta dicotomía, como en el caso de la Reurbanización de la Villa 20, donde se logran consensos en la demolición de viviendas preexistentes (y relocalización de familias en nuevas viviendas linderas), para poder realizar la apertura de calles que vinculen el barrio con el resto de la comuna (en este sentido es necesario también contextualizar que las viviendas en las villas carecen de regularización dominial que permita a sus usuarios ejercer una condición de propietarios). Contrariamente esta idea se cuestiona en el caso del Parque Lineal, donde para lograr la concreción del proyecto, numerosas familias fueron desplazadas hacia otras barrios fuera del radio de influencia de este.

Para el caso del Jardín Circunvalar, la estrategia de gestión del proyecto se valió de los recursos de participación ciudadana al punto que se los convirtió en emblema de la operación urbanística, entendiendo que los consensos logrados y los aportes obtenidos de la ciudadanía constituían un insumo en sí mismo que creaba sinergias positivas en la construcción del nuevo parque metropolitano. Sin embargo, algunos actores sociales se manifestaron críticamente respecto de las estrategias participativas desplegadas, que habrían dejado de lado algunos dispositivos creados previamente ${ }^{48}$.

Respecto a los modos de participación de actores sociales, los tres casos reflejan las pujas internas de intereses dentro de las propias áreas de la administración pública en relación a los proyectos, y queda en evidencia la necesidad de desnaturalizar la visión monolítica y simplificada de su accionar. Para el caso de Villa 20, la figura de la Mesa por la Urbanización de la Villa 20 toma un rol destacable a modo de "denunciante y veedora" de los acuerdos entre el GCBA, las empresas constructoras y los vecinos, el cumplimiento de plazos, etc.

Para el Jardín Circunvalar, la sinergia entre la Alcaldía de Medellín y la Empresa de Desarrollo Urbano - EDU, junto con la posibilidad de contar con una empresa de servicios públicos - EPM - poseedora de recursos económicos, permite un despliegue de gran amplitud en materia de desarrollo de planos, proyectos y obras. Sin embargo, otras reparticiones, como el Consejo Territorial de Planeación - CTP - se consideraron desplazadas en este proyecto.

Respecto al Parque Lineal Suburbio, el proyecto fue realizado por el Ministerio de Desarrollo Urbano y Vivienda de la nación, mientras que el municipio de Guayaquil parece haber tenido poca injerencia. Como consecuencia de esto, y sumado a problemáticas sociales estructurales vinculadas con el consumo de drogas, el estado actual de los parques muestra deterioro en las infraestructuras y limitaciones en su uso por parte de los habitantes locales ${ }^{49}$.

48 "Vale la pena llamar la atención sobre la inconformidad que representantes de diferentes sectores de la población manifestaron en torno a la incidencia de la participación ciudadana en el proyecto del Jardín Circunvalar de Medellín, proyecto piloto del Cinturón Verde. Si bien se valoran los esfuerzos de la Administración por vincular a la población en la formulación del proyecto a través de diferentes ejercicios y técnicas, realmente ¿qué ha quedado de los distintos aportes de la ciudadanía? Es oportuno que la Administración y el Consejo Territorial de Planeación (CTP) mantengan un diálogo fluido y constante con los pobladores, pues ese espacio se creó precisamente para socializar los planes de la Alcaldía, en los cuales se enmarcan proyectos como el del Cinturón Verde. Por esa razón, extraña que la presidenta del CTP haya afirmado que solo hacía poco tiempo el proyecto había sido explicado en detalle por la Alcaldía". Extraído de la publicación del Institut de Recherche et Débat sur la Gouvernance - IRG del año 2013. "El Cinturón verde de Medellín. Debate sobre el futuro de las laderas de la ciudad". Disponible en: http://www.institutgouvernance.org/spip.php?article149\&lang=es

49 "...Al igual que este juego, muchos otros están deteriorados y dañados por completo en algunos tramos que componen el parque lineal del suburbio y el de la isla Trinitaria. Este proyecto, que integra el plan Guayaquil Ecológico, del Gobierno central, empezó a inaugurarse en el 2013 y buscó recuperar once zonas de ribera del estero Salado. Sin embargo, el paso de los años, el poco mantenimiento y el descuido ciudadano generan problemas. Xavier Salgado, activista ecológico local, manifiesta que los moradores salen a botar desechos tanto orgánicos como de construcción en las riberas. A su vez, el descuido se junta con la inseguridad. Muchos de los juegos están destruidos a causa de los "hacheros" (consumidores de la droga H) de la zona, que los roban para comprar el estupefaciente, incluso hasta el césped sintético ha sido sustraído de varias partes a lo largo de este parque". Párrafo extraído del la publicación: " Peligro y temor en parques lineales del estero Salado con robos y daños" del portal Web El Universo, enero 2018. Disponible en : https://www.eluniverso.com/guayaquil/2018/01/27/nota/6585967/peligro-temor-parques-lineales-robos-danos 
Finalmente, los casos de estudio presentados constatan la existencia de puntos de coincidencia entre las estrategias y los roles del EP en contextos de desigualdad en las distintas ciudades estudiadas, a la vez que reflejan la importancia en el desarrollo de PEP como parte de las políticas urbanísticas. La reflexión, los procesos proyectuales, los modos de participación comunitaria, de ejecución y de preservación de estos deben ser entonces correctamente planificados y legitimados, para lograr una imbricación efectiva entre ambas, que regule de manera eficaz las diferentes escalas de abordaje, en una visión integradora. 


\section{6 . Bibliografía}

\section{a - Autores consultados:}

- $\quad$ BORJA, E. (2013). "Aunque verde, todo cinturón aprieta". Medellín. Reflexión K.

- $\quad$ BRAND. P.(2010) "El Urbanismo Social de Medellín, Colombia". Medellín.

- $\quad$ CHANCY BRUN, E. (2015). "Tejiendo los hilos de la memoria: historia local de Medellín desde los pobladores de la periferia. Comunas 3,6 y 8, periodo 1970 a 2014" Medellín. PROYECTO BUPPE Universidad de Antioquia.

- $\quad$ CONTRERAS VELASCO,K. (2016) "Plan de rehabilitación urbano. ecológica con enfoque sistémico y participativo, caso de estudio del sector sureste del estéreo salado de puerto lisa de Guayaquil" Guayaquil. Universidad de Guayaquil.

- $\quad$ DUQUE FRANCO, I. (2014). "Políticas públicas, urbanismo y fronteras invisibles. Las disputas por el control espacial en Medellín". Scripta Nova, Vol. VXIII. Numero 493

- $\quad$ ECHEVERRI, A. (2015). Entrevista en profundidad. Espacio Público de Medellín. Medellín. Cómo Vamos

- $\quad$ ECHEVERRI. A. y M. ORSINI. F. (2010). "Informalidad y Urbanismo Social en Medellín". Medellín: Universidad Eafit.

- $\quad$ KULLOCK, D Y SZKLOWIN, C. (1995) "Apuntes para una política de espacios públicos" en Reflexiones, los espacios públicos. Buenos Aires, Argentina: Secretaría de extensión universitaria y bienestar estudiantil FADU UBA.

- $\quad$ MOTTA, J.; ALMANSI, F. et al (2017): "Gestión y planificación por proceso-proyecto para el mejoramiento de villas y asentamientos de gran escala. El caso de la Re-Urbanización de Villa 20 en la CABA". publicado en Medio Ambiente y Urbanización, Volumen 86, №1, pp. 145-168(24). Publisher: IIEDAmérica Latina

- $\quad$ Norwegian Institute for Water Research (2012) "Plan de rehabilitación para el estero Salado Guayaquil, Ecuador. Guyaquil. NIVA.

- NUÑEZ CRISTIANSEN, J. (2013) "Reordenamiento, recuperación e intervención en las riberas del estero salado" Guayaquil. Guayaquil. MAS ciudad.

- $\quad$ PEREZ JARAMILLO, J. (2013). "Estrategias de Transformación. El caso de Medellín -Colombia". Villavicencio. Meta.

- $\quad$ REESE, E. (2006): "La situación actual de la gestión urbana y la agenda de las ciudades en la Argentina". En Medio Ambiente y Urbanización. Volumen 65. № 1. Instituto Internacional de Medio Ambiente y Desarrollo, IIED América Latina. Vicente López, Argentina.

- $\quad$ RIVERA JARA, A. (2015) "Estudio urbano de densificación habitacional y diseño de vivienda progresiva ubicada en el sector de Malvinas Guayaquil)" Guayaquil. Universidad de Guayaquil.

- $\quad$ SANTAMARIA LUCERO, A.(2015). "Estudio del espacio urbano y la intervención ecológica con participación ciudadana en los barrios del suburbio oeste de la ciudad de Guayaquil." Guayaquil. Universidad de Guayaquil.

- $\quad$ SZAJNBERG, D. (1999) "Planificación participativa y gestión consensuada de nuevos espacios verdes urbanos para Boedo, Almagro y Caballito", en Publicación de la Asamblea Permanente por los Espacios Verdes Urbanos (APEVU).

- $\quad$ TORO, M. (2013): "Que es el regeneración urbana integral". Sitio web "La Ciudad viva". Disponible en: http://www.laciudadviva.org/blogs/?p=19123

- $\quad$ TRUJILLO URREGO, C. (2017). Medellín cultura: Lectura de una marca de la cuidad a través de la transformación urbanística y la apropiación del edificio cultural. Medellín. Universidad Nacional de Colombia. - U.R.B.A.N. (2013). Re habitar la montaña. Estrategias y procesos para un hábitat sostenible en las laderas de Medellín. Medellín. Impresos Ltda.

\section{b - Documentos oficiales consultados}

\section{b.1 - Reurbanización Villa 20}

- $\quad$ Consejo del Plan Urbano Ambiental - COPUA (2006). "Documento Plan Urbano Ambiental". Buenos Aires.

- GCBA-Ministerio de Desarrollo Urbano Subsecretaría de Planeamiento. "Modelo Territorial Buenos Aires 2010 - 2060", Buenos Aires

- $\quad$ GCBA-Ministerio de Desarrollo Urbano Subsecretaría de Planeamiento."Informe preliminar para el desarrollo del Plan Maestro Comuna 8",Buenos Aires

- $\quad$ GCBA.(2015). Secretaría de Hábitat e Inclusión. "De villa a Barrio". 
- $\quad$ Censo Nacional de Población, Hogares y Viviendas 2010:

https://www.indec.gob.ar/ftp/cuadros/poblacion/censo2010_tomo1.pdf

- $\quad$ "Informe censo Barrio 20" - Instituto de la vivienda - IVC - Gobierno de la Ciudad de Buenos aires GCBA: http://www.buenosaires.gob.ar/sites/gcaba/files/informe_censo_barrio_20_final.pdf

\section{b.2 - Parque Lineal suburbio}

- Ministerio de Espacio y Ambiente. (2010) "Generación y restructuración de áreas verdes para la ciudad de Guayaquil" Guayaquil. MdEyA.

- Instituto Nacional de Estadísticas y Censos. INEC:

http://www.ecuadorencifras.gob.ec/institucional/home/

- Instituto Nacional de Estadísticas y Censos - INEC - Proyección de Población ecuatoriana:

http://www.ecuadorencifras.gob.ec/proyecciones-poblacionales/

- $\quad$ Plan de Ordenamiento Territorial de la Provincia de Guayas. Disponible en:

http://www.guayas.gob.ec/dmdocuments/ley-de-transparencia/literal-k/Plan-de-Ordenamiento-T-2013.pdf

- Instituto Nacional de Estadísticas y Censos - INEC - Reporte de Pobreza y Desigualdad:

http://www.ecuadorencifras.gob.ec/documentos/webinec/POBREZA/2017/Junio/Informe\%20pobreza\%20y\% 20desigualdad\%20-\%20jun\%202017\%2014072017.pdf

\section{b.3 - Jardín Circunvalar}

- Empresa de Desarrollo Urbano - EDU. (2015) "Documento Jardín Circunvalar de Medellín".

- Departamento Administrativo Nacional de Estadística 2016 -DANE : https://www.dane.gov.co/ - DOCUMENTO TÉCNICO DE SOPORTE POT [ACUERDO 46/2006] MUNICIPIO DE MEDELLíN. http://sisbib.unmsm.edu.pe/BibVirtualData/publicaciones/geologia/Vol7_N13/Pdf/a05.pdf

\section{c - Leyes consultadas}

- $\quad$ Ley $\mathrm{N}^{\circ} 2930 / 08$, B.O.C.B.A. N 3091, Pub. 13/11/2008 - Plan Urbano Ambiental de Buenos Aires

- Ley N $\quad 5705$ - Reurbanización, Zonificación e Integración socio-urbana de la Villa 20 - 24/112016

- Proyecto de ley (2013): Generación y restauración de áreas verdes para la cuidad de Guayaquil:

"Guayaquil Ecológico". Ministerio de desarrollo urbano y vivienda. Ministerio de Ambiente de Guayaquil.

- $\quad$ Plan de Ordenamiento Territorial de Medellín- POT (2006), "De la revisión y ajuste al Plan de Ordenamiento Territorial".

- $\quad$ Resolución No. 461. (2014). "Cinturón Verde Metropolitano".

- CONSTITUCION POLITICA DE COLOMBIA-1991. https://www.registraduria.gov.co/IMG/pdf/constitucio-politicacolombia-1991.pdf

\section{d - Artículos periodísticos}

\section{d.1 - Reurbanización Villa 20:}

- $\quad$ Diario Clarín: "Plan de viviendas para la Villa 20". Publicado el 2 de marzo de 2016. Disponible en: https://www.clarin.com/ciudades/plan-viviendas-villa_0_EJ488xknl.html

- Diario Clarín: "La Villa 20 de Lugano, una de las más conflictivas y con edificios de hasta cinco pisos". Publicado el 3 de julio de 2015. Disponible en: https://www.clarin.com/ciudades/villa_20-villa_luganovisita-cristina fernandez de kirchner_0 rk532LtP7g.html

- $\quad$ Diario Clarín: "La reurbanización de la Villa 20, en suspenso". Publicado el 22 de junio de 2016. Disponible en: https://www.clarin.com/ciudades/reurbanizacion-villa-suspenso_0_Vk2TjqMrW.html - Sitio web Buenos Aires en línea: "Maquieyra: Este es el gobierno que más invirtió en urbanización de villas" - publicado el 20 de noviembre de 2016, disponible en: http://www.bairesenlinea.com.ar/ultimasnoticias/maquieyra-este-es-el-gobierno-que-mas-invirtio-en-urbanizacion-de-villas/

- $\quad$ Diario Página 12: "Ley de urbanización sin mapa". Publicado el 25 de noviembre de 2016. Disponible en: https://www.pagina12.com.ar/5136-ley-de-urbanizacion-sin-mapa

- Diario La Nación: "Villa 20: a casi tres años de la toma, los vecinos esperan las nuevas viviendas" Publicado el 8 de mayo de 2017. Disponible en: http://www.lanacion.com.ar/2021533-villa-20-a-casi-tresanos-de-la-t 


\section{d.2. Parque Lineal suburbio:}

- $\quad$ Diario El Comercio: "Jorge Glas tuvo su propia agenda en fiestas de Guayaquil y solo coincidió en un acto con el Presidente". Publicado el 27 de julio del 2017. Disponible en:

http://www.elcomercio.com/actualidad/jorgeglas-agenda-fiestas-guayaquil-leninmoreno.html

- Diario El Telégrafo: "462 casas listas para su entrega en Socio Vivienda " (Publicado 16/12/2017) http://www.eltelegrafo.com.ec/noticias/guayaquil/1/462-casas-listas-para-su-entrega-en-socio-vivienda

- Diario El Telégrafo: "Dos obras cambian el rostro del sur y el suburbio de Guayaquil". Publicada el 23 de Julio del 2015. Disponible en: http://www.eltelegrafo.com.ec/noticias/guayaquil/10/dos-obras-cambianel-rostro-del-sur-y-el-suburbio-de-guayaquil

- $\quad$ Diario El Telégrafo: "El sur y suburbio de Guayaquil contarán con dos nuevos tramos de parques lineales". Publicado el 9 de julio del 2015. Disponible en:

http://www.eltelegrafo.com.ec/noticias/guayaquil/10/el-sur-y-suburbio-de-guayaquil-contaran-con-dosnuevos-tramos-de-parques-lineales

- $\quad$ Diario El Telégrafo: "Invasiones, constante histórica de Guayaquil" (Publicado 26/05/2013)

http://www.eltelegrafo.com.ec/noticias/guayaquil/10/invasiones-constante-historica-de-guayaquil

- Diario El Telégrafo: "Parques lineales y nuevos puentes son las obras del 2011".Publicado el 7 de enero del 2011. Disponible en: http://www.eluniverso.com/2011/01/07/1/1445/parques-lineales-nuevospuentes-son-obras-2011.html

- Diario El Universo: "Inaugurado sexto tramo del parque lineal". Publicado el 18 de enero del 2017. Disponible en: http://www.eluniverso.com/noticias/2017/01/18/nota/6002578/inaugurado-sexto-tramoparque-lineal

- Diario Expreso. "La pobreza extrema crece más en Guayaquil, Cuenca y Machala": (Publicado 18/07/2017). Disponible en: http://www.expreso.ec/economia/la-pobreza-extrema-crece-mas-en-guayaquilcuenca-y-machala-BF1557650

- Diario Expreso. "La reubicación de familias junto al estero no avanza y estas siguen descargando": (Publicado 11/03/2016) http://www.expreso.ec/guayaquil/la-reubicacion-de-familias-junto-al-estero-noavanza-y-estas-siguen-descargando-DJ139533

- Diario Expreso: "La reubicación de familias junto al estero no avanza y estas siguen descargando" publicado el 11 de marzo del 2016. Disponible en: http://www.expreso.ec/guayaquil/la-reubicacion-defamilias-junto-al-estero-no-avanza-y-estas-siguen-descargando-DJ139533

- Diario La República: "MIDUVI entrega en Guayaquil parques lineales en Trinipuerto y estero Mogollón" (Publicado: 24/07/2015) https://www.larepublica.ec/blog/sociedad/2015/07/24/miduvi-entrega-enguayaquil-parques-lineales-en-trinipuerto-y-estero-mogollon/

- Diario Oro Medios: "MÁS DE 120 MIL HABITANTES DEL SUR Y SUBURBIO DE GUAYAQUIL SE BENEFICIAN CON PARQUES LINEALES". Publicado el 24 de julio del 2015. Disponible en:

http://www.oromedios.com/mas-de-120-mil-habitantes-del-sur-y-suburbio-de-guayaquil-se-benefician-conparques-lineales/

- $\quad$ Web Radio Hualcavilca: "MIDUVI entrega a Guayaquil los parques lineales de Trinipuerto y estero Mogollón por sus fiestas de fundación". Publicado el 23 de julio del 2015. Disponible en:

http://radiohuancavilca.com.ec/noticias/2015/07/23/miduvi-entrega-a-guayaquil-los-parques-lineales-detrinipuerto-y-estero-mogollon-por-sus-fiestas-de-fundacion/\#

\section{d.3. Jardín Circunvalar:}

- $\quad$ Agencia de prensa IPC: "Dudas sobre el Cinturón Verde generan malestar" (Publicado: 24/08/2012) http://www.ipc.org.co/agenciadeprensa/index.php/2012/08/24/dudas-sobre-el-cinturon-verde-generanmalestarl

- $\quad$ Colombia Informa: "Medellín, una 'ciudad para la vida' de unos cuantos" (Publicado 03/02/2017) http://www.colombiainforma.info/\%EF\%BB\%BFmedellin-una-ciudad-para-la-vida-de-unos-cuantos/ - D Diario el Colombiano:" ¿Cinturón verde o gris?, polémica por intervención en la ladera" (Publicado 08/06/2013)

http://www.elcolombiano.com/historico/cinturon_verde_o_gris_polemica_por_intervencion_en_la_laderaHCEC_250214

- $\quad$ Diario El Mundo: "En cuatro cerros iniciará el Jardín Circunvalar de Medellín". Publicado el 3 de julio del 2013. Disponible en: 
http://www.elmundo.com/portal/noticias/obras/en_cuatro_cerros_iniciara_el_jardin_circunvalar_de_medellin. php

- Diario el Tiempo: "Cinturón Verde de Medellín da sus primero pasos, pero siguen dudad" (Publicado 14/12/2012) http://www.eltiempo.com/archivo/documento/CMS-12450976

- Diario el Tiempo: "Golondrinas, el ultimo eco parque turístico del Jardín Circunvalar". (Publicado: 1/07/2017) http://www.eltiempo.com/colombia/medellin/golondrinas-el-ultimo-ecoparque-turistico-del-jardincircunvalar-94340

- $\quad$ Diario El Tiempo: "Inauguran tres obras del Jardín Circunvalar en Medellín". Publicado el 13 de febrero del 2015. Disponible en: http://www.eltiempo.com/archivo/documento/CMS-15239856

\section{e - Otras fuentes}

- $\quad$ Convocatoria al Primer Seminario Internacional sobre Espacio Público: "diseño violencia e ilusiones urbanas", a realizarse en México DF en febrero de 2018. Información disponible en:

http://seminarioespaciopublico.com/programa-de-actividades/

- $\quad$ Dirección de Uso del Espacio y Vía Pública de Guayaquil:

http://www.guayaquil.gob.ec/direcci\%C3\%B3n-de-uso-del-espacio-y-via-publica

- Ministerio de Ambiente y Espacio Público del GCBA - MAyEP.

http://www.buenosaires.gob.ar/ambienteyespaciopublico

- Página web de EDU "Inició la construcción de la segunda fase del Camino de la Vida, obra del Jardín Circunvalar, entre El Faro y Golondrinas". Publicado el 15 de mayo del 2015-Disponible en: http://www.edu.gov.co/site/actualidad/118-lo-ultimo/1323-inicio-la-construccion-de-la-segunda-fase-delcamino-de-la-vida-obra-del-jardin-circunvalar-entre-el-faro-y-golondrinas

- $\quad$ Página web de EDU. Empresa de Desarrollo Urbano de Medellín. Publicado el 3 de junio del 2015.http://www.edu.gov.co/site/actualidad/118-lo-ultimo/1330-jardin-circunvalar-de-medellin-es-reconocidocomo-buena-practica-para-enfrentar-el-cambio-climatico-en-colombia

- $\quad$ Página web de EDU. Empresa de Desarrollo Urbano de Medellín: “El Jardín Circunvalar de Medellín, nominado al premio Lápiz de Acero 2015".Publicado el 23 de abril del 2015. Disponible en: http://www.edu.gov.co/site/actualidad/1306-el-jardin-circunvalar-de-medellin-nominado-al-premio-lapiz-deacero-2015

- $\quad$ Página web de Instituto de investigación y debate sobre la gobernanza. Publicado el 8 de agosto del 2013. Disponible en: http://www.institut-gouvernance.org/es/experienca/fiche-experienca-59.html

- Pagina web del Gobierno de la Ciudad de Buenos Aires - GCBA: http://www.buenosaires.gob.ar/

- $\quad$ Pagina web del Mapa Interactivo del Gobierno de la Ciudad de Buenos Aires - GCBA: https://mapa.buenosaires.gob.ar/

- PERFIL SOCIOECONÓMICO DE MEDELLÍN. ENCUESTA CALIDAD DE VIDA-2013:

http://www.metropol.gov.co/observatorio/Publicaciones/Perfil/Perfil\%20Municipal_Medellin.pdf

- Secretaría de Cultura Ciudadana Proyecto Memoria y Patrimonio 2008: "La Comuna 8 MEMORIA Y TERRITORIO":

http://bibliotecadigital.udea.edu.co/bitstream/10495/4561/6/QuicenoToroNatalia_2008_Comuna8MemoriaTer ritorio.pdf

- $\quad$ Sitio web de la Comisión Económica para América Latina y el Caribe - CEPAL. Disponible en:

https://www.cepal.org/es/articulos/2016-america-latina-caribe-es-la-region-mas-desigual-mundo-comosolucionarlo

- $\quad$ Subsecretaria de Espacio Público de Medellin:

https://www.medellin.gov.co/irj/portal/medellin?NavigationTarget=navurl://93ea1dacab70f2427429cca669c8d 9fa

- $\quad$ Web del Ministerio de Desarrollo Urbano y Vivienda: "Los Parques Lineales del tramo 4 y 5 del Estero Salado están por concluirse" . Disponible en: http://www.habitatyvivienda.gob.ec/los-parqueslineales-del-tramo-4-y-5-del-estero-salado-estan-por-concluirse/

- $\quad$ Web del Municipio de Guayaquil. Disponible en: http://www.guayaquil.gob.ec

- Web oficial de Colombia: http://www.guayaquil.gob.ec/divisi\%C3\%B3n

- Web Oficial de la Alcaldía de Medellín: https://www.medellin.gov.co/irj/portal/medellin

- Worpress Jardín Circunvalar https://cinturonverde.wordpress.com/about/ 